\title{
Synthesis and Optical Properties of 1,1-Binaphthyl-Thiophene Alternating Copolymers with Main Chain Chirality
}

\author{
Kohsuke Kawabata and Hiromasa Goto* \\ Division of Materials Science, Faculty of Pure and Applied Sciences, University of \\ Tsukuba, Tsukuba, Ibaraki, 305-8573, Japan
}

Correspondence to H. Goto, e-mail: gotoh@ims.tsukuba.ac.jp Fax: +81-298-53-4490

\begin{abstract}
A series of axially chiral 1,1- binaphthyl-thiophene copolymers was synthesized by Migita-Kosugi-Stille polycondensation and electrochemical polymerization. The polymers exhibit circular dichroism not only in the ultraviolet region but also visible region, both in solution and film states. Optical and electrochemical properties of the polymers are in good agreement with theoretical results obtained by density functional theory calculations. Although effective conjugation of the polymers was cleaved at the orthogonally oriented two naphthalene rings in the 1,1-binaphthyl unit, the electrochemically synthesized polymer film shows good electrochemical redox behavior with repeatable changes in optical absorption and circular dichroism. The changes in circular dichroism may reflect a change in a dihedral angle of the binaphthyl unit caused by reorientation of conjugated main chains between oxidized and neutral states.
\end{abstract}

Keywords; $\pi$-conjugated polymer, 1,1- binaphthyl, axial chirality, electrochromism

\section{Introduction}

Conjugated polymers are of great interest as nonlinear optical, fluorescent, and chromic materials. ${ }^{1-3}$ Such optical properties of conjugated polymers can be modulated by modifying chemical structure of the polymers. ${ }^{4}$ Among various kinds of conjugated polymers, polythiophene derivatives are the most promising because of thermal and environmental stability and structural versatility ${ }^{5}$, which are known as, for example, poly(3-alkylthiophene)s ${ }^{6}, \quad$ poly(3,4-ethylenedioxythiophene) $s^{7}$ and polyisothianaphthenes. ${ }^{8,9}$ The optical properties of conjugated polymers are also tunable by electrochemical redox process which leads to repeatable changes in the electronic state and chemical structure of the polymers.

Chiral polymers have also attracted much attention because of their chiroptical activity $^{10}$, asymmetric separation ${ }^{11}$ and recognition properties ${ }^{12}$, and various types of chiral structure. Particularly, chiral conjugated polymers can exhibit circular dichroism (CD) in the visible region, which can be applied to chiroptical materials. To date, a great number of chiral conjugated polymers, such as chiral side chain type ${ }^{13-16}$, helical main chain type ${ }^{17}$, and chiral aggregation type polymers ${ }^{18-20}$, have been synthesized. One of the most effective ways to induce such chiral structures in polymers is to introduce chiral moieties into the polymer structures. To date, several conjugated polymers with 
main chain axial chirality were synthesized by introducing 1,1'-binaphthyl derivatives well-known as chiral molecules with axial chirality into conjugated polymer backbones. $^{21-26}$

In this study, we report synthesis of a series of binaphthyl-thiophene copolymers via Migita-Kosugi-Stille polycondensation and electrochemical polymerization. Modifying copolymerized thiophene units gave fine-tuned optical and electrochemical properties of resulting polymers, which are in good agreement with theoretical results obtained by density functional theory (DFT) calculations. The electrochemically synthesized polymers exhibited good electrochemical redox behavior resulting in electrochromism accompanied by repeatable changes in CD. Tuning chiroptical activity via redox driven mechanical change in the dihedral angle of binaphthyl units in the main chain can be achieved.

\section{Experimental \\ Characterization}

The chemical structures of the monomers were confirmed by ${ }^{1} \mathrm{H}$ and ${ }^{13} \mathrm{C}$ NMR spectroscopy with AVANCE-600 (Bruker), JNM-ECS 400 (Jeol), and JNM-EX 270 (Jeol). The chemical shifts in deuterated chloroform were reported against tetramethylsilane internal standard. Ultraviolet-visible (UV-vis) absorption spectra were taken with UV-3100PC (Shimadzu). A concentration of the polymers was $2 \mathrm{mg} / \mathrm{L}$ in THF. Polymer films were casted from chloroform solutions. CD measurements were performed with a JASCO J-720. PL spectra were collected employing F-4500 spectrometer (Hitachi). IR absorption spectra were obtained with FT/IR 550 (JASCO) by using the $\mathrm{KBr}$ method. Matrix-assisted laser desorption ionization time-offlight mass spectroscopy (MALDI-TOF-MS)

analysis was conducted using TOF/TOF 5800 (AB SCIEX) with dithranol as a matrix. Cyclic voltammetry measurements were carried out with $\mu$ AUTOLAB TYPE Ш (ECO Chemie). Electrolyte solutions contained $0.1 \mathrm{M}$ of TBAP in acetonitrile. Molecular weights of the polymers were determined by GPC against polystyrene standards by using THF as the solvent with $5 \mu \mathrm{m}$-MIXED-D column (Polymer Laboratories), PU-980 HPLC pump (Jasco), and MD-915 multiwavelength detector (Jasco).

\section{Monomer Synthesis.}

\section{2,5-Di(trimethylstannyl)thiophene (1)}

To a solution of thiophene (2.10 g, $25.0 \mathrm{mmol})$ and $N, N, N$, $N$ '-tetramethylethylenediamine (TMEDA) (11.62 g, $100 \mathrm{mmol})$ in THF (50 mL) was added 1.6 $\mathrm{M} n$-butyllithium in hexane (32.8 mL, $52.5 \mathrm{mmol}$ ) through a dropping funnel over $10 \mathrm{~min}$ at $-78^{\circ} \mathrm{C}$ under argon atmosphere. After addition of the butyllithium, the reaction mixture was refluxed at $50{ }^{\circ} \mathrm{C}$ for $1 \mathrm{~h}$ to afford white slurry, and cooled to $-78{ }^{\circ} \mathrm{C}$ again. To the slurry was added a solution of trimethylstannyl chloride (10.46 g, $52.5 \mathrm{mmol}$ ) in THF (30 mL) dropwise over $10 \mathrm{~min}$. Then, the mixture was gradually warmed up to room temperature and stirred for $12 \mathrm{~h}$. After the reaction, water (50 mL) was added to the mixture and the mixture was extracted with ether. The organic layer was dried over magnesium sulfate and filtrated. After the evaporation of the solvent, recrystallization from methanol gave a white solid ( $2.43 \mathrm{~g}, 10.6 \mathrm{mmol}$, yield $=43 \%) .{ }^{1} \mathrm{H}$ NMR (400 MHz, $\delta$ from TMS (ppm), $\mathrm{CDCl}_{3}$ ): $\delta 0.37$ (s, 2H, $-\mathrm{CH}_{3}$ ), 7.37 (s, 2H, 3,5H(thiophene)). ${ }^{13} \mathrm{C}$ NMR (100 MHz, $\delta$ from TMS (ppm), $\mathrm{CDCl}_{3}$ ): $\delta-8.2,135.8$, 
143.0.

\section{1,3-Dihydro-benzo[c]thiophene (2)}

To a refluxed solution of sodium sulfide nonahydride (26.14 g, $109 \mathrm{mmol}$ ) in ethanol $(250 \mathrm{~mL})$ and water $(50 \mathrm{~mL})$ was added 1,2-bischloromethylbenzene (12.31 g, 70.3 mmol) through a Sohxlet extractor and the mixture was refluxed for $40 \mathrm{~min}$. After evaporation of the solvent, the residual tan-colored oil was extracted with dichloromethane and water, and the organic layer was dried over magnesium sulfate. Evaporation of the solvent in vacuo to afford yellow solid (5,91 g, $43.4 \mathrm{mmol}$, yield = $62 \%)$. This compound was used in the next step without further purification. ${ }^{1} \mathrm{H}$ NMR (400 MHz, $\delta$ from TMS (ppm), $\left.\mathrm{CDCl}_{3}\right): \delta 4.27\left(\mathrm{~s}, 4 \mathrm{H},-\mathrm{CH}_{2^{-}}\right), 7.18-7.27(\mathrm{~m}, 4 \mathrm{H}$, 3,4,5,6-H). ${ }^{13} \mathrm{C}$ NMR (100 MHz, $\delta$ from TMS (ppm), $\left.\mathrm{CDCl}_{3}\right): \delta$ 38.0, 124.7, 126.7, 140.3.

\section{1,3-Dihydro-benzo[c]thiophene 2-oxide (3)}

To a solution of compound $2(1.88 \mathrm{~g}, 13.8 \mathrm{mmol})$ in ethanol $(47 \mathrm{~mL})$ was added a solution of sodium periodate $(2.96 \mathrm{~g}, 13.8 \mathrm{mmol})$ in water $(39 \mathrm{~mL})$ dropwise at $0{ }^{\circ} \mathrm{C}$ with vigorous stirring. After stirring for $3 \mathrm{~h}$, a white inorganic salt was filtered off. Evaporation of the solvent followed by recrystallization from ethyl acetate/hexane gave a colorless plate $(1.53 \mathrm{~g}, 10.1 \mathrm{mmol}$, yield $=73 \%) .{ }^{1} \mathrm{H}$ NMR $(400 \mathrm{MHz}, \delta$ from TMS (ppm), $\left.\mathrm{CDCl}_{3}\right): \delta 4.16$ (d, $2 \mathrm{H}, \mathrm{C}-\mathrm{H}$ (the opposite side of oxygen atom), $J=16.2 \mathrm{~Hz}$ ), 4.30 (d, $2 \mathrm{H}, \mathrm{C}-H$ (the same side of oxygen atom, $J=16.3 \mathrm{~Hz}$ ), 7.31-7.34 (m, 2H, 4,5- $H$ ), 7.38 (dd, $2 \mathrm{H}, 3,6-H, J=3.4,5.4 \mathrm{~Hz}$ ). ${ }^{13} \mathrm{C}$ NMR (100 MHz, $\delta$ from TMS (ppm), $\mathrm{CDCl}_{3}$ ): $\delta$ 59.4, 126.6, 128.4, 135.1 .

\section{1,3-Di(trimethylstannyl)isothianaphthene (5)}

Compound 3 (1.51 g, $9.9 \mathrm{mmol}$ ) and aluminum oxide powder (2.40 g, $23.6 \mathrm{mmol})$ were mixed and finely crushed in a mortar. Sublimation of the mixture under reduced pressure gave isothianaphthene (4) as a white solid (1.00 g, $7.5 \mathrm{mmol}$, yield $=75 \%$ ). Freshly sublimated compound 4 (1.00 g, $7.5 \mathrm{mmol})$ and TMEDA (2.17 g, $18.6 \mathrm{mmol})$ were dissolved in THF (22 mL) under a argon atmosphere. To the mixture was added $2.5 \mathrm{M} n$-butyllithium in hexane $(7.0 \mathrm{~mL}, 17.5 \mathrm{mmol})$ at $-78{ }^{\circ} \mathrm{C}$ through a dropping funnel over $10 \mathrm{~min}$, then stirred vigorously at room temperature for $1 \mathrm{~h}$. The mixture was cooled to $-78{ }^{\circ} \mathrm{C}$ again, and a solution of trimethylstannyl chloride $(3.80 \mathrm{~g}, 19.0 \mathrm{mmol})$ in THF $(10 \mathrm{~mL})$ was added dropwise to the mixture. The mixture was slowly warmed up to room temperature and stirred for $12 \mathrm{~h}$. The mixture was poured into a saturated ammonium hydrogen carbonate aqueous solution $(70 \mathrm{~mL})$ and separated. The aqueous layer was extracted with ether twice and the combined organic layer was dried over magnesium sulfate. After evaporation of the solvent, recrystallization from petroleum ether $\left(30 \sim 70{ }^{\circ} \mathrm{C}\right)$ gave pale yellow solid $(1.73 \mathrm{~g}, 3.75 \mathrm{mmol}$, yield $=50 \%) .{ }^{1} \mathrm{H} \mathrm{NMR}$ (400 MHz, $\delta$ from TMS (ppm), $\mathrm{CDCl}_{3}$ ): $\delta 0.49$ (s, 18H, $-\mathrm{CH}_{3}$ ), 7.07 (dd, 2H, 5,6H, $J=$ 3.0, $6.6 \mathrm{~Hz}$ ), 7.67 (dd, $2 \mathrm{H}, 4,7 \mathrm{H}, J=2.8,6.8 \mathrm{~Hz}) .{ }^{13} \mathrm{C}$ NMR $(100 \mathrm{MHz}, \delta$ from TMS (ppm), $\left.\mathrm{CDCl}_{3}\right): \delta-8.0,122.6,123.9,137.0,146.7$.

\section{2,5-Di(tributylstannyl)-3,4-ethylenedioxythiophene (6)}

To a solution of 3,4-ethylenedioxythiophene (3.48 g, $23.5 \mathrm{mmol})$ and TMEDA (10.90 g, $93.8 \mathrm{mmol}$ ) in THF (50 mL) was added 1.6 M n-butyllithium in hexane (31.0 mL, 49.6 
mmol) through a dropping funnel over $20 \mathrm{~min}$ at $-78{ }^{\circ} \mathrm{C}$ under a argon atmosphere. The mixture was stirred for $1 \mathrm{hr}$ at room temperature to afford a white slurry. To the slurry was added tributylstannyl chloride $(16.5 \mathrm{~g}, 50.7 \mathrm{mmol})$ in THF $(10 \mathrm{~mL})$ dropwise at $-78{ }^{\circ} \mathrm{C}$, and the mixture was slowly warmed up to room temperature. After stirring for $12 \mathrm{~h}$, water $(100 \mathrm{~mL})$ was added and the solution was extracted with ether twice. The organic layer was dried over magnesium sulfate. After evaporation of the solvent, the residual liquid was purified by silica gel column chromatography (eluent: hexane/triethylamine $=19 / 1)$ to afford a colorless oil (0.94 g, $1.4 \mathrm{mmol}$, yield $=6 \%$ ), however a large part of target compound was decomposed through the column. ${ }^{1} \mathrm{H}$ NMR $\left(270 \mathrm{MHz}, \delta\right.$ from TMS (ppm), $\left.\mathrm{CDCl}_{3}\right): \delta 0.87\left(\mathrm{t}, 18 \mathrm{H},-\mathrm{CH}_{3}, J=7.26 \mathrm{~Hz}\right.$ ), 1.05-1.10 (m, 12H, $\left.-\mathrm{CH}_{2}-\mathrm{CH}_{3}\right), 1.26-1.39\left(\mathrm{~m}, 12 \mathrm{H},-\mathrm{CH}_{2}-\mathrm{C}_{2} \mathrm{H}_{5}\right), 1.50-1.62(\mathrm{~m}, 12 \mathrm{H}$, $-\mathrm{CH}_{2}-\mathrm{C}_{3} \mathrm{H}_{7}$ ), 4.11 (s, $\left.4 \mathrm{H}, \mathrm{O}-\mathrm{C}_{2} \mathrm{H}_{4}-\mathrm{O}\right) .{ }^{13} \mathrm{C}$ NMR (68 MHz, $\delta$ from TMS (ppm), $\mathrm{CDCl}_{3}$ ): $\delta$ 10.5, 13.7, 27.2, 29.0, 64.5, 115.6, 148.0.

\section{5,5-Ditrimethylstannyl-2,2'-bithiophene (7)}

To a solution of 2,2'-bithiophene $(4.0 \mathrm{~g}, 24.1 \mathrm{mmol})$ in THF $(110 \mathrm{~mL})$ was added $1.6 \mathrm{M}$ $n$-butyl lithium in hexane ( $35 \mathrm{~mL}, 56.0 \mathrm{mmol}$ ) dropwise at $-78{ }^{\circ} \mathrm{C}$, then the mixture was stirred at room temperature for $1 \mathrm{~h}$. The mixture was cooled to $-78{ }^{\circ} \mathrm{C}$ again, and trimethylstannyl chloride (11.6 g, $58.2 \mathrm{mmol})$ in THF $(10 \mathrm{~mL})$ was added dropwise. The mixture was gradually warmed up to room temperature and stirred for $12 \mathrm{~h}$. The mixture was extracted with ether twice, and the organic layer was dried with magnesium sulfate. Purification by silica gel column chromatography (eluent: hexane) followed by recrystallization from ethanol gave a white solid $(5.37 \mathrm{~g}, 10.9 \mathrm{mmol}$, yield $=46 \%) .{ }^{1} \mathrm{H}$ NMR (400 MHz; CDCl $\mathrm{CDMS}_{3} \delta 0.38$ (s, 18H, -CH3), 7.08 (d, 2H, $J=3.3 \mathrm{~Hz}$ ), 7.27 (d, $2 \mathrm{H}, J=3.36 \mathrm{~Hz}) .{ }^{13} \mathrm{C} \mathrm{NMR}\left(100 \mathrm{MHz} ; \mathrm{CDCl}_{3}\right.$; TMS $) \delta-8.24,124.86,135.85,137.07$, 143.04 .

\section{4,4'-n-Dioctyl-2,2'-bithiophene (8)}

To a solution of 3-octylthiophene (7.85 g, $40 \mathrm{mmol}$ ) and TMEDA (5.12 g, $44 \mathrm{mmol})$ in THF (120 mL) was added $n$-butyllithium (1.6 M in hexane) $(25 \mathrm{~mL}, 40 \mathrm{mmol})$ dropwise over $5 \mathrm{~min}$ at $0 \mathrm{C}^{\circ}$. Then, the mixture was refluxed at $50{ }^{\circ} \mathrm{C}$ for $1 \mathrm{~h}$. After the mixture was cooled to $-78^{\circ} \mathrm{C}$, copper(II) chloride $(5.92 \mathrm{~g}, 44 \mathrm{mmol})$ was added in one portion, and stirred at $-78^{\circ} \mathrm{C}$ for $40 \mathrm{~min}$. Then, the reaction mixture was gradually warmed up to room temperature, and stirred for $6 \mathrm{~h}$. The reaction was quenched with $2 \mathrm{M}$ hydrochloric acid $(80 \mathrm{~mL})$. The reaction mixture was extracted with ether and dried over magnesium sulfate. Purification by silica gel column chromatography followed by recrystallization from hexane gave a pale yellow solid (3.60 g, $9.2 \mathrm{mmol}$, yield = 46\%). ${ }^{1} \mathrm{H}$ NMR (400 $\mathrm{MHz}, \mathrm{CDCl}_{3}$ ): $\delta=0.88$ (t, $6 \mathrm{H}, J=6.9 \mathrm{~Hz}$ ), $1.27-1.31$ (m, 20H), 1.61 (quintet, $4 \mathrm{H}, J=$ $7.4 \mathrm{~Hz}$ ), 2.56 (t, $4 \mathrm{H}, J=7.6 \mathrm{~Hz}), 6.76$ (d, $2 \mathrm{H}, J=1.2 \mathrm{~Hz}), 6.98(\mathrm{~d}, 2 \mathrm{H}, J=1.4 \mathrm{~Hz}) .{ }^{13} \mathrm{C}$ NMR (100 MHz, $\mathrm{CDCl}_{3}$ ): $\delta=14.11,22.68,29.27,29.33,29.44,30.41,30.54,31.90$, 118.71, 124.82, 137.39, 144.00.

\section{4,4'-Dioctyl-5,5'-bistrimethylstannyl-2,2'-bithiophene (9)}

To a solution of $8(2.74 \mathrm{~g}, 7.0 \mathrm{mmol})$ in dry THF $(120 \mathrm{~mL})$ was added $n$-butyllithium (1.6 $\mathrm{M}$ in hexane) $(9.7 \mathrm{~mL}, 15.5 \mathrm{mmol})$ dropwise over $5 \mathrm{~min}$ at $78{ }^{\circ} \mathrm{C}$. After stirred at $-78{ }^{\circ} \mathrm{C}$ for $15 \mathrm{~min}$, the mixture was warmed up to room temperature and stirred for $1 \mathrm{~h}$. After the reaction mixture was cooled to $78^{\circ} \mathrm{C}$ again, trimethyltin chloride $(3.29 \mathrm{~g}$, 
$16.5 \mathrm{mmol})$ in THF (16 mL) was added to the mixture over $5 \mathrm{~min}$. The mixture was gradually warmed up to room temperature and stirred for $8 \mathrm{~h}$. After the reaction, water $(100 \mathrm{~mL})$ was added to the mixture, and the organic layer was extracted with ether and dried over magnesium sulfate. Evaporation followed by drying in vacuo gave a yellow oil (4.43 g, $6.2 \mathrm{mmol}$, yield $=88 \%) .{ }^{1} \mathrm{H}$ NMR (400 MHz, $\left.\mathrm{CDCl}_{3}\right): \delta 0.37(\mathrm{~s}, 18 \mathrm{H}), 0.88$ (t, $6 \mathrm{H}, J=6.9 \mathrm{~Hz}$ ), 1.27-1.31 (m, 20H), 1.58 (quintet, $4 \mathrm{H}, J=7.5 \mathrm{~Hz}$ ), 2.54 (t, $4 \mathrm{H}, J=$ $7.8 \mathrm{~Hz}$ ), $7.11(\mathrm{~s}, 2 \mathrm{H}) .{ }^{13} \mathrm{C}$ NMR $\left(100 \mathrm{MHz}, \mathrm{CDCl}_{3}\right): \delta-7.88,14.12,22.69,29.26,29.54$, 29.62, 31.89, 32.01, 32.87, 125.98, 130.93, 142.71, 151.60 .

\section{(R)-6,6'-Dibromo-2,2'-didodecyloxy-1,1'-binaphthyl (10)}

A solution of (R)-6,6'-Dibromo-1,1'-bi-2,2'-naphthol (2.00 g, $4.47 \mathrm{mmol})$, 1-bromododecane (2.24 g, $9.00 \mathrm{mmol})$, potassium carbonate $(2.48 \mathrm{~g}, 18.0 \mathrm{mmol})$, and potassium iodide (3.00 g, $18.0 \mathrm{mmol})$ in 2-butanone $(50 \mathrm{~mL})$ was refluxed for $24 \mathrm{~h}$. After the reaction, the mixture was extracted with ether and dried over magnesium sulfate. The crude product was purified by silica gel column chromatography (eluent: chloroform $/$ hexane $=1 / 1)$ to afford a colorless oil $(1.168 \mathrm{~g}, 1.50 \mathrm{mmol}$, yield $=33 \%)$. ${ }^{1} \mathrm{H}$ NMR (400 MHz, $\left.\mathrm{CDCl}_{3}\right): \delta 0.87-1.43\left(\mathrm{~m}, 46 \mathrm{H},-\mathrm{C}_{10} \mathrm{H}_{20}-\mathrm{CH}_{3}\right), 3.86-3.98(\mathrm{~m}, 4 \mathrm{H}$, $\left.-\mathrm{O}-\mathrm{CH}_{2^{-}}\right), \quad 6.97$ (d, 2H, 8,8'-H(binaphthyl), $\left.J=8.8 \mathrm{~Hz}\right), 7.25$ (dd, 2H, 7,7'-H(binaphthyl), $J=2.4,9.2 \mathrm{~Hz}$ ), 7.40 (d, 2H, 3,3'-H(binaphthyl), $J=9.2 \mathrm{~Hz}$ ), 7.82 (d, 2H, 4,4'-H(binaphthyl), $J=9.2 \mathrm{~Hz}$ ), 7.99 (d, 2H, 5,5'-H(binaphthyl), $J=1.6 \mathrm{~Hz}$ ). ${ }^{13} \mathrm{C}$ NMR (100 MHz; $\mathrm{CDCl}_{3}$; TMS) $\delta 14.15,22.72,25.66,29.14,29.30,29.40,29.51$, 29.54, 29.67, 29.69, 31.96, 69.56, 116.42, 117.22, 120.05, 127.13, 128.36, 129.76, $130.20,132.57,154.77$.

\section{(R)-2,2'-Didodecyloxy-6,6'-di(2-thienyl)-1,1'-binaphthyl (11)}

A solution of 10 (0.156 g, $0.20 \mathrm{mmol})$ 2-tributylstannylthiophene $(0.157 \mathrm{~g}, 0.42 \mathrm{mmol})$, and $\mathrm{Pd}\left(\mathrm{PPh}_{3}\right)_{4}(0.01 \mathrm{~g}, 0.008 \mathrm{mmol})$ in toluene solution were refluxed or $24 \mathrm{~h}$. After the reaction, crude product was purified by silica gel (containing $10 \mathrm{v} / \mathrm{v} \%$ of potassium carbonate) column chromatography (eluent: hexane/chloroform $=6 / 4$ ) to afford colorless oil (0.096 g, $0.12 \mathrm{mmol}$, yield = $61 \%) .{ }^{1} \mathrm{H}$ NMR ( $400 \mathrm{MHz} ; \mathrm{CDCl}_{3}$; TMS) $\delta$ 0.87-1.29 (m, $42 \mathrm{H},-\mathrm{C}_{9} \mathrm{H}_{18}-\mathrm{CH}_{3}$ ), 1.39-1.43 (m, 4H, -O- $\mathrm{CH}_{2}-\mathrm{CH}_{2}-$ ), 3.91-3.99 (m, 4H, -O-CH $2^{-}$), 7.08 (dd, 2H, 4-H(thiophene), $\left.J=3.6,4.8 \mathrm{~Hz}\right), 7.18$ (d, 2H, 3,3'-H(binaphtyhl), $J=8.8 \mathrm{~Hz}$ ), 7.26 (dd, 2H, 5,5'-H(thiophene), $J=1.2,5.2 \mathrm{~Hz}$ ), 7.34 (dd, 2H, 3,3'-H(thiophene), $J=1.0,3.4 \mathrm{~Hz}$ ), 7.42 (d, 2H, 4,4'-H(binaphtyhl), $J=9.2$ Hz), 7.48 (dd, 2H, 7,7'-H(binaphtyhl), $J=1.6,8.8$ Hz), 7.94 (d, 2H, 7,7'-H(binaphtyhl), $J=8.8 \mathrm{~Hz}$ ), 8.06 (d, 2H, 5,5'-H(binaphtyhl), $J=2.0 \mathrm{~Hz}) .{ }^{13} \mathrm{C}$ NMR $\left(100 \mathrm{MHz}\right.$; $\mathrm{CDCl}_{3}$; TMS) $\delta 14.15$, 22.72, 25.70, 29.20, 29.39, 29.53, 29.56, 29.66, 31.94, 69.70, 116.29, 120.45, 122.80, 124.30, 124.37, 124.72, 126.08, 128.00, 129.27, 129.29, 129.47, 133.50, 144.82, 154.78.

\section{A general procedure for Migita-Kosugi-Stille polymerization reaction.}

Ditrialkylstannylated monomers $(0.1 \mathrm{mmol})$ and compound $10(0.078 \mathrm{~g}, 0.1 \mathrm{mmol})$ and tetrakis(triphenylphosphine)palladium $(0)\left(\mathrm{Pd}\left(\mathrm{PPh}_{3}\right)_{4}\right)(0.006 \mathrm{~g}, 0.005 \mathrm{mmol})$ were dissolved in toluene $(1 \mathrm{~mL})$, and the mixture was refluxed at $90{ }^{\circ} \mathrm{C}$. After $72 \mathrm{~h}$, the mixture was washed with methanol $(200 \mathrm{~mL})$ followed by centrifugation and decantation of the supernatant solution. This procedure was repeated three times. The residue was dried in vacuo to afford target polymers. P(Bn-T) (38 mg, yield $=54 \%$ ), 
P(Bn-ITN) (20 mg, yield = 26\%), P(Bn-EDOT) (37 mg, yield = 49\%), P(Bn-BT) (20 mg, yield = 27\%), $\mathbf{P}(\mathbf{B n}-\mathbf{B 8 T})(66 \mathrm{mg}$, yield $=66 \%)$.

\section{Electrochemical polymerization.}

$\mathrm{EP}(\mathrm{Bn}-\mathrm{BT})$ was synthesized by electrochemical polymerization of compound $\mathbf{1 1}$ using repeated potential cycling with three-electrode system which consisted of an ITO coated glass working electrode, an $\mathrm{Ag} / \mathrm{Ag}^{+}$reference electrode, and a platinum wire counter electrode. An electrolyte solution consisted of TBAP $(0.1 \mathrm{M})$ and the monomer (1.0 $\mathrm{mM}$ ) in acetonitrile solution. A scan rate is $100 \mathrm{mVs}^{-1}$. After polymerization, a yellow thin film was obtained on the ITO electrode.

\section{Calculations.}

The highest occupied molecular orbital (HOMO), the lowest unoccupied molecular orbital (LUMO) and their energy levels of model compounds for the polymers in the ground state were calculated by density functional theory (DFT) method employing Becke's three-parameter set with Lee-Yang-Parr correlation functional (B3LYP) and the 6-31G* basis set, which is implemented in Spartan '04 package.

\section{Results and Discussion}

\section{Synthesis of monomers}

A series of bistrialkylstannylated monomers (1,5,6,7,9) and (R)-6,6'-dibromo-2,2'-didodecyloxy-1,1'-binaphthyl (10) were synthesized as monomers for Migita-Kosugi-Stille polycondensation reactions (Scheme 1). The bistrialkylstannylated monomers were prepared via double-lithiation of corresponding thiophene derivatives at $-78{ }^{\circ} \mathrm{C}$ followed by quench with trialkylstannyl chloride. $\mathbf{1 0}$ was synthesized via Williamson etherification from (R)-6,6'-dibromo-1,1'-bi-2,2'-naphthol and 1-bromododecane. (R)-2,2'-Didodecyloxy-6,6'-di(2-thienyl)-1,1'-binaphthyl (11) was synthesized via Stille cross coupling reaction between $\mathbf{1 0}$ and 2-tributylstannylthiophene as a monomer for electrochemical polymerization.

\section{Polymerization}

Migita-Kosugi-Stille polycondensation reactions between 6,6'-dibromo-2,2'-dioctyloxy-1,1'-binaphthyl and a series of bis-trialkylstannylated monomers in the presence of a palladium catalyst were carried out (Scheme 2). The resulting polymers were soluble in THF and chloroform. Table 1 summarizes the results of the polymerization reactions. The GPC measurements (against a polystyrene standard) using THF as an eluent for the polymers show number-average molecular weights of around $3900-4800 \mathrm{gmol}^{-1}$ and weight-average molecular weight of around 4600 - $7700 \mathrm{gmol}^{-1}$. The chemical structures of the polymers were confirmed by ${ }^{1} \mathrm{H}$ NMR spectroscopy (Figure S4 - S8) and MALDI-TOF-MS (Figure S9 - S13).

\section{Infrared (IR) absorption spectroscopy}

Figure 1 shows IR spectra of the polymers and the binaphthyl monomer 10. The polymers show relatively strong absorptions at 2924 and $2852 \mathrm{~cm}^{-1}$ due to $\mathrm{C}-\mathrm{H}$ stretching of a long alkyl chain attached to the binaphthyl units. $\mathrm{P}(\mathrm{Bn}-\mathrm{B} 8 \mathrm{~T})$ shows 
intense absorption at this band because of additional long alkyl chain in the dioctylbithiophene units. The polymers also show an absorption band at $1092 \mathrm{~cm}^{-1}$, which is due to C-O-C stretching in the binaphthyl units. Particularly, $\mathrm{P}(\mathrm{Bn}-\mathrm{EDOT})$ shows relatively strong absorption band at the wavenumber because of the ethylenedioxy group of the EDOT units. $\mathrm{P}(\mathrm{Bn}-\mathrm{T}), \mathrm{P}(\mathrm{Bn}-\mathrm{BT})$, and $\mathrm{P}(\mathrm{Bn}-\mathrm{B} 8 \mathrm{~T})$ show absorption bands at $795-800 \mathrm{~cm}^{-1}$ due to $\mathrm{C}-\mathrm{H}$ bending vibration (out of plane) at $\beta$-positions of thiophene unit. ${ }^{27,28} \mathrm{P}(\mathrm{Bn}$-EDOT) shows a strong absorption band at 1092 $\mathrm{cm}^{-1}$. An absorption band of $\mathrm{P}(\mathrm{Bn}-\mathrm{ITN})$ at $1659 \mathrm{~cm}^{-1}$ is assignable to skeletal vibration of a fused benzene ring of the isothianaphthene unit. These characteristic absorption bands indicate that the polymers have desired chemical structures.

\section{Optical properties}

Figure 2 shows CD, UV-vis absorption, and PL spectra of the monomer $\mathbf{1 0}$ and the polymers in THF solution and film states. Absorption maximum and onset and emission maximum wavelengths are summarized in Table 2. The binaphthyl monomer shows a clear couplet with negative Cotton effect at $245 \mathrm{~nm}$ and a positive one at $233 \mathrm{~nm}$ (negative couplet), which corresponds to a strong optical absorption band at around 240 $\mathrm{nm}$. This couplet is due to the coupling between ${ }^{1} \mathrm{~B}_{\mathrm{b}}$ transitions of two naphthalene rings of the binaphthyl monomer. The relationship between CD spectra and conformation of binaphthyl was well discussed both theoretically and experimentally in the literature. ${ }^{29-35}$ A sign of the couplet is determined not only by the $(R)$ or $(S)$ configuration but also the dihedral angle between the two naphthalene rings. As for the monomer 10 bearing the $(R)$-configuration, the observed negative couplet at around 240 $\mathrm{nm}$ indicates that the dihedral angle between two naphthalene rings is smaller than $100^{\circ}$. The polymers in THF solution show new absorption bands at long wavelengths and show red-shift in maximum emission wavelengths due to development of the conjugation. $\mathrm{P}(\mathrm{Bn}-\mathrm{T})$ shows absorption bands at $297 \mathrm{~nm}$ and $364 \mathrm{~nm}$ and emission at $419 \mathrm{~nm}$ and $444 \mathrm{~nm}$, while $\mathrm{P}(\mathrm{Bn}-\mathrm{BT})$ shows an absorption band at $404 \mathrm{~nm}$ and $462 \mathrm{~nm}$ and $492 \mathrm{~nm}$. These results are in good agreement with previous reports on binaphthyl-mono and bithiophene copolymers in spite of different molecular weight, ${ }^{36,37}$ indicating that effective conjugation length of the polymers are independent from molecular weight more than several thousand because of limited conjugation between the orthogonally oriented binaphthyl units. $\mathrm{P}(\mathrm{Bn}-\mathrm{BT})$ has a longer effective conjugation in the main chain than $\mathrm{P}(\mathrm{Bn}-\mathrm{T})$ because of an increase in the number of thiophene rings in the monomer unit. On the other hand, $\mathrm{P}(\mathrm{Bn}-\mathrm{B} 8 \mathrm{~T})$ with flexible alkyl chains as substituents shows an absorption band at a short wavelength $(350 \mathrm{~nm})$ as compared to $\mathrm{P}(\mathrm{Bn}-\mathrm{BT})$ and $\mathrm{P}(\mathrm{Bn}-\mathrm{T})$ although $\mathrm{P}(\mathrm{Bn}-\mathrm{B} 8 \mathrm{~T})$ has two thiophene rings in the monomer repeat unit. This can be due to the fact that steric hindrance of alkyl side chains of the thiophene units increases the dihedral angle between thiophene and naphthalene rings.

Optimized geometry, HOMO, and LUMO of model compounds in a gas state, which consisted of the thiophene spacers sandwiched with two 2,2'-dimethoxy-1,1'-binaphthalene, were calculated by a DFT method (Figure 4). The dihedral angle in optimized geometry of a model compound for $\mathrm{P}(\mathrm{Bn}-\mathrm{B} 8 \mathrm{~T})$ was calculated to be $46^{\circ}$, whereas $26^{\circ}$ and $23^{\circ}$ were calculated for the model compounds of $\mathrm{P}(\mathrm{Bn}-\mathrm{T})$ and $\mathrm{P}(\mathrm{Bn}-\mathrm{BT})$, respectively. This result can explain why $\mathrm{P}(\mathrm{Bn}-\mathrm{B} 8 \mathrm{~T})$ has a shorter effective conjugation length as compared to $\mathrm{P}(\mathrm{Bn}-\mathrm{BT})$ and $\mathrm{P}(\mathrm{Bn}-\mathrm{T})$, whereas the dihedral angle between EDOT and naphthalene rings in $\mathrm{P}(\mathrm{Bn}-\mathrm{EDOT})$ was calculated to 
be $15^{\circ} . \mathrm{P}(\mathrm{Bn}-\mathrm{EDOT})$ shows an absorption band at $377 \mathrm{~nm}$, which is more intense than that of $\mathrm{P}(\mathrm{Bn}-\mathrm{T})$. Generally, isothianaphthene units in conjugated polymers reduce bandgap energy due to conjugation over the fused benzene ring and stabilization of quinonoid structure of the thiophene moiety. ${ }^{38}$ The DFT calculation results for $\mathrm{P}(\mathrm{Bn}-\mathrm{ITN})$ gave the smallest energy gap $(3.03 \mathrm{eV})$ among the polymers, despite a wide dihedral angle of $40^{\circ}$ between isothianaphthene and naphthalene rings. Indeed, as expected, absorption onset of $\mathrm{P}(\mathrm{Bn}-\mathrm{ITN})$ in THF is located at longer wavelengths (482 $\mathrm{nm}$ ) than for other polymers. However, intensity of the absorption band at long wavelengths is somewhat low. It should be noted that in the DFT calculation results for the model compounds, HOMOs and LUMOs were localized only at coplanar naphthalene-thiophenes-naphthalene moieties, which indicated conjugation breaking at the orthogonally oriented naphthalenes. This limited conjugation is supported by the fact that $\mathrm{P}(\mathrm{Bn}-\mathrm{ITN})$ and 1,3-bis-(6-dodecyloxy-naphthalen-2-yl)-isothianaphthene (compound $\mathbf{1 3}$ in Supplementary Information), and $\mathrm{P}(\mathrm{Bn}-\mathrm{B} 8 \mathrm{~T})$ and 5,5'-bis-(6-dodecyloxy-naphthalen-2-yl)-4,4'-dioctyl-[2,2']bithiophenyl (compound $\mathbf{1 4}$ in Supplementary Information) show absorption onsets at the same wavelengths, respectively (Figure S1 and S2). Hence, the naphthalene-thiophene-naphthalene moieties can be regarded as discrete chromophores.

In the CD spectra, the polymers show negative couplet around $240 \mathrm{~nm}$, indicating that the polymers maintain the axial conformation at binaphthyl moiety after polymerization, whereas the polymers show weak Cotton effects at long wavelengths, which are attributable to exciton coupling between naphthalene-thiophene-naphthalene chromophores. In a film state, absorption spectra of the polymers were red-shifted. This red shift was due to an increase of coplanarity in the naphthalene-thiophene-naphthalene unit and development of $\pi$-stacking between the chromophores, which are derived from aggregation in the solid state. The red shift is also observable in the CD and the PL spectra of the polymers. The negative sign and splitting width of the couplet at $240 \mathrm{~nm}$ of the polymers in the film state shows the same values as the polymers in the solution, indicating the dihedral angle between two naphthalene is not changed after the film formation. The red-shift value in the PL spectra is greater than that in the UV-vis absorption spectra after the film formation due to interchromophoric interaction in the film state. ${ }^{39}$ Among the series of the polymers, $\mathrm{P}(\mathrm{Bn}-\mathrm{B} 8 \mathrm{~T})$ shows relatively small change in absorption, CD, and PL spectra after film formation. This indicates that the main chains of $\mathrm{P}(\mathrm{Bn}-\mathrm{B} 8 \mathrm{~T})$ are entangled and have weak interchromophoric interactions in both solution and film states because of steric hindrance of long alkyl chains at octylthiophene units. While, in the film, other polymers show increase of the CD intensity at longer wavelength couplets as compared to the couplet at $240 \mathrm{~nm}$ after film formation, especially for $\mathrm{P}(\mathrm{Bn}-\mathrm{EDOT})$. This is due to a strong interchromophoric interaction of $\mathrm{P}(\mathrm{Bn}-\mathrm{EDOT})$ which has high coplanarity in the conjugated chromophore. In $\mathrm{P}(\mathrm{Bn}-\mathrm{T})$ and $\mathrm{P}(\mathrm{Bn}-\mathrm{BT})$, negative Cotton effects were observed at long wavelengths in solution, while the first positive and new second negative Cotton effects were observed at long wavelengths in the film.

\section{Voltammetric behavior of the polymers}

In order to examine electrochemical properties of the polymers, cyclic voltammetry of the polymers in the film state was carried out by using an $\mathrm{Ag} / \mathrm{Ag}^{+}$reference electrode in $0.1 \mathrm{M}$ tetrabutyl ammonium perchlorate (TBAP) acetonitrile solution. Figure 3 shows 
cyclic voltammograms of the polymers calibrated with the ferrocene/ferrocenium $\left(\mathrm{Fc} / \mathrm{FC}^{+}\right)$redox potential. Among the polymers, $\mathrm{P}(\mathrm{Bn}-\mathrm{EDOT})$ has the lowest oxidation potential of $0.44 \mathrm{~V}$ (vs. $\mathrm{Fc} / \mathrm{Fc}^{+}$) because of electro-donating ethylenedioxy substituents in the EDOT units. Under the assumption that the $\mathrm{Fc} / \mathrm{Fc}^{+}$redox potential is $4.8 \mathrm{eV}$ below the vacuum level ${ }^{40}$, the HOMO energy levels of the polymers can be calculated by using the following equation: $E_{\mathrm{HOMO}}=-\left(E_{\text {onset,ox }}+4.8\right) \mathrm{eV}$. The LUMO energy levels of the polymers can be calculated using optical energy gaps $\left(\Delta E_{\mathrm{opt}}\right)$ of the polymers by the following equation: $E_{\mathrm{LUMO}}=E_{\mathrm{HOMO}}+\Delta E_{\mathrm{opt}}$. The HOMO and LUMO energy levels estimated by the electrochemical method, and optical energy gaps are summarized in Table 3. A comparison of the experimental results with results obtained by DFT calculations in an energy diagram are summarized in Figure 4. Experimentally estimated HOMO and LUMO values show good agreement with those of DFT calculation results except for P(Bn-ITN). Experimentally, P(Bn-ITN) has somewhat a deep HOMO value and a large energy gap as compared to the DFT calculation results. This can be due to differences between the gas phase conditions employed in the DFT calculations and the solid state conditions employed in the measurements.

\section{Electropolymerized P(Bn-BT) (EP(Bn-BT))}

$\mathrm{P}(\mathrm{Bn}-\mathrm{BT})$ was synthesized by electrochemical polymerization (Scheme 2). Figure 5 shows cyclic voltammograms for electrochemical polymerization of compound 11. An oxidation current onset of the first cycle corresponds to the oxidation potential of the monomer of $0.69 \mathrm{~V}$ (vs. $\mathrm{Fc} / \mathrm{Fc}^{+}$). After the second cycle oxidation current onset was shifted to $0.57 \mathrm{~V}$ (vs. $\mathrm{Fc} / \mathrm{Fc}^{+}$), and the current response intensity increased with increase in the number of cycles, indicating the progress of polymerization reaction. Generally, as polymerization reaction proceeds, an oxidation current onset decreases due to extension of effective conjugation length with growth of the main chain. However, in the case of EP(Bn-BT), where EP stands for electropolymerization, no decrease in oxidation current onset was observed after the second cycle, indicating saturation of the effective conjugation. This result also supports the conclusion that the effective conjugation of the polymer was cleaved at the orthogonally oriented two naphthalene rings. The oxidation onset potential at $0.57 \mathrm{~V}$ (vs. $\mathrm{Fc} / \mathrm{Fc}^{+}$) is observed for $\mathrm{EP}(\mathrm{Bn}-\mathrm{BT}$ ). This observation is in good agreement with the results for the chemically polymerized $\mathrm{P}(\mathrm{Bn}-\mathrm{BT})$.

Figure 6 shows the IR spectra of compound $\mathbf{1 1}$ and EP(Bn-BT) in a reduced state. $\mathrm{EP}(\mathrm{Bn}-\mathrm{BT})$ shows the same absorption bands as those of the chemically polymerized $\mathrm{P}(\mathrm{Bn}-\mathrm{BT})$, and absorption bands similar to those of the monomer. However, an absorption band at $692 \mathrm{~nm}$ observed for the monomer ( $\delta_{\mathrm{C}-\mathrm{H}}$ at $\alpha$-positions of thiophenes) disappeared after electrochemical polymerization. Additionally, an absorption band at $796 \mathrm{~nm}$ which is characteristic of $\delta_{\mathrm{C}-\mathrm{H}}$ at $\beta$-positions of 2,5-substituted thiophenes appeared after the polymerization. ${ }^{27,28}$ These results confirmed that electrochemical polymerization of compound $\mathbf{1 1}$ afforded EP(Bn-BT) via a coupling reaction between $\alpha$-positions of thiophene units of the monomers.

MALDI-TOF-MS measurements using dithranol as a matrix was carried out to o molecular weight of EP(Bn-BT). Figure 7 shows a MALDI-TOF-MS spectrum of EP(Bn-BT). The spectrum shows a certain pattern with a periodicity of $785 \mathrm{of} \mathrm{m} / \mathrm{z}$, which corresponds to a molecular weight of the monomer unit (785.20). In the measurements, the peaks up to 7065 of $\mathrm{m} / \mathrm{z}$, which corresponds to 9 mers, were detected. 
The peak intensity of the spectra decreased with an increase in the $m / z$ value. This result indicates that the MALDI-TOF-MS measurements for the electrosynthesized polymer can evaluate molecular weights of the low molecular weight fraction of the polymer.

$\mathrm{EP}(\mathrm{Bn}-\mathrm{BT})$ was obtained as an electroactive film deposited on an indium-tin-oxide (ITO) glass electrode, which exhibits repeatable color change by electrochemical redox process (electrochromism) accompanied by a repeatable change in CD. Figure 8 shows $\mathrm{CD}$ and UV-vis absorption spectra of the EP(Bn-BT) film at various applied potentials during electrochemical redox process. The spectra at short wavelengths $(<300 \mathrm{~nm})$ could not be obtained because of the optical absorption of ITO glass electrode in the ultra-violet range. In the reduced state, the polymer shows an absorption band at $410 \mathrm{~nm}$ due to $\pi-\pi^{*}$ transition of naphthalene-bithiophene-naphthalene chromophores, which is similar to that of chemically polymerized $\mathrm{P}(\mathrm{Bn}-\mathrm{BT})$ in the film state. However, in the CD spectra, EP(Bn-BT) shows a negative couplet at around $410 \mathrm{~nm}$, which is the opposite sign to that of $\mathrm{P}(\mathrm{Bn}-\mathrm{BT})$ in the film state although the polymer possesses the same chemical structure and stereo-configuration of the binaphthyl unit. The differences in the CD spectra suggest that the chemically and electrochemically polymerized polymers have different aggregation structure in the film, which is derived from the differences in the film formation processes. The $\mathrm{P}(\mathrm{Bn}-\mathrm{BT})$ film was prepared by a cast method, while the EP(Bn-BT) film was directly deposited by electrochemical oxidation process on the substrate via radical coupling reaction. During an oxidation process, $\mathrm{EP}(\mathrm{Bn}-\mathrm{BT})$ showed a new absorption band at around $600-700 \mathrm{~nm}$, which is accompanied by a decrease in intensity of the absorption band at short wavelengths. This new band is due to formation of a radical cation in the naphthalene-bithiophene-naphthalene unit. Simultaneously, in the CD spectra, a new negative couplet appeared at around $600-700 \mathrm{~nm}$, and the intensity of the original negative couplet at $410 \mathrm{~nm}$ decreased. The new negative couplet can be due to interchromophoric exciton coupling between the radical cationic naphthalene-bithiophene-naphthalene units. During reduction process, a change in the UV-vis and the CD spectra was observed in the reverse direction against the electrochemical oxidation process. The dihedral angle of the binaphthyl unit can be tuned by a possible mechanical change in the form of the main chain upon the redox process. Figure 9 shows optimized geometries of the model compound for $\mathrm{P}(\mathrm{Bn}-\mathrm{BT})$ in both neutral and radical cationic states obtained by the DFT calculation. These geometries show differences in the length and coplanarity of the naphthalene-bithiophene-naphthalene unit in the neutral and radical cationic states. The naphthalene-bithiophene-naphthalene unit in the radical cationic state has a shorter length and a more planar conformation than that in the neutral state because of structural contribution from quinonoid character in the radical cationic state rather than benzenoid character in the neutral state. ${ }^{41}$ In the film, this reorientation by the redox process can drive mechanical change in the main chain, resulting in a change of the dihedral angle of the binaphthyl unit as shown in Figure 10. Furthermore, in film formation process for $\mathrm{EP}(\mathrm{Bn}-\mathrm{BT})$ through electrochemical oxidative coupling reaction, the planar conformation of the chromophores in the radical cationic state can lead better packing structure of the chromophores than that in $\mathrm{P}(\mathrm{Bn}-\mathrm{BT})$ film prepared by cast method.

\section{Conclusion}

A series of axially chiral binaphthyl-thiophene alternating copolymer derivatives were 
synthesized by Migita-Kosugi-Stille polycondensation and electrochemical polymerization. The polymers showed chiroptical activity in the visible range. These optical properties are tunable by modification of thiophene monomer units in the design of the polymer. The effective conjugation in the main chain of the polymers is cleaved at the orthogonally oriented two naphthalene rings resulting in discrete naphthalene-thiophene-naphthalene chromophoric units. The chemically polymerized polymers in the film showed larger Stokes shifts than that in a THF solution, indicating occurrence of interchromophoric interactions in the film. Chemically polymerized $\mathrm{P}(\mathrm{Bn}-\mathrm{BT})$ and electrochemically polymerized $\mathrm{EP}(\mathrm{Bn}-\mathrm{BT})$ in the film state showed different CD spectra, despite the same chemical structure. This result can be explained by different aggregation mechanisms for the films obtained by a cast method (from a chloroform solution) and electrodeposition. EP(Bn-BT) electrodeposited on an ITO glass electrode showed good electrochromic behavior accompanied by repeatable changes in the CD spectra, in which the Cotton effect due to polaronic radical cation species in the naphthalene-bithiophene-naphthalene chromophore was observed in the oxidized state. The electrochemical redox process allows a change in the electronic state of the main chain and dihedral angle of binaphthyl unit, mechanically providing tunable chiroptical activity of the polymers. This result shows that electrosynthesis of main-chain-type axially chiral polybinaphthyl conjugated polymers is a good strategy for obtaining electroactive chiroptical materials.

Acknowledgement. We would like to thank Chemical Analysis Center of University of Tsukuba and Glass Work Shop of University of Tsukuba. This research was supported by the Japan Society for the Promotion of Science, Grant in-Aid for Scientific Research, 22550161. K. Kawabata is a research fellow of the Japan Society for the Promotion of Science.

\section{References and Notes}

1 M. G. Vivas, S. L. Nogueira, H. Santos Silva, N. M. Barbosa Neto, A. Marletta, F. Serein-Spirau, S. Lois, T. Jarrosson, L. De Boni, R. A. Silva and C. R. Mendonca, J. Phys. Chem. B, 2011, 115, 12687-12693.

2 X. Li, X. Zhang, W. Li, Y. Wang, T. Liu, B. Zhang and W. Yang, J. Mater. Chem., 2011, 21, 3916-3924.

3 E. P. Knott, M. R. Craig, D. Y. Liu, J. E. Babiarz, A. L. Dyer and J. R. Reynolds, J. Meter. Chem., 2012, 22, 4953-4962.

4 Y. K. Jung, H. Kim, J. H. Park, J. Lee, S. K. Lee, Y. S. Lee and H. K. Shim, J. Polym. Sci. Part A, 2008, 46, 3573-3590.

5 J. Roncali, Chem. Rev., 1992, 92, 711-738.

6 I. Osaka and R. D. McCullough, Acc. Chem. Res., 2008, 41, 1202-1214.

7 L. B. Groenendaal, F. Jonas, D. Freitag, H. Pielartzik and J. R. Reynolds, Adv. Mater., 2000, 12, 481-494.

8 F. Wudl, M. Kobayashi and A. J. Heeger, J. Org. Chem., 1984, 49, 3382-3384.

9 M. Lapkowski, R. Kiebooms, J. Gelan, D. Vanderzande, A. Pron, T. P. Nguyen, G. Louarn and S. Lefrant, J. Mater. Chem., 1997, 7, 873-876.

10 J. M. Yu, T. Sakamoto, K. Watanabe, S. Furumi, N. Tamaoki, Y. Chenb and T. Nakano, Chem. Commun., 2011, 47, 3799-3801.

11 K. Tamura, T. Miyabe, H. Iida and E. Yashima, Polym. Chem., 2011, 2, 91-98. 
12 X. Du, J. Liu, J. Deng and W. Yang, Polym. Chem., 2010, 1, 1030-1038.

13 V. Percec, M. Peterca, J. G. Rudick, E. Aqad, M. R. Imam and P. A. Heiney, Chem. Eur. J., 2007, 13, 9572-9581.

14 K. Shinohara, S. Yasuda, G. Kato, M. Fujita and H. Shigekawa, J. Am. Chem. Soc., 2001, 123, 3619-3620.

15 K. P. R. Nilsson, J. D. M. Olsson, P. Konradsson and O. Inganäs, Macromolecules, 2004, 37, 6316-6321.

16 B. M. W. Langeveld-Voss, R. A. J. Janssen and E. W. Meijer, J. Mol. Struct., 2000, 521, 285-301.

17 E. Schwartz, M. Koepf, H. J. Kitto, R. J. M. Nolte and A. E. Rowan, Polym. Chem., 2011, 2, 33-47.

18 P. A. Korevaar, S. J. George, A. J. Markvoort, M. M. J. Smulders, P. A. J. Hilbers, A. P. H. J. Schenning, T. F. A. De Greef and E. W. Meijer, Nature, 2012, 481, 492-494.

19 W. Zhang, K. Yoshida, M. Fujiki and X. Zhu, Macromolecules, 2011, 44, 5105-5111.

20 T. Shiraki, A. Dawn, Y. Tsuchiya, T. Yamamoto and S. Shinkai, Chem. Commun., 2012, 48, 7091-7093.

21 Z. An, J. Yin, N. Shi, H. Jiang, R. Chen, H. Shi and W. Huang, J. Polym. Sci. A, 2010, 48, 3868-3879.

22 L. Feng, Y. Wang, F. Liang, M. Xu and X. Wang, Tetrahedron, 2011, 67, 3175-3180.

23 J. Deng, C. Zhou, C. Chen, N. Song and Z. Su, Macromolecules, 2008, 41, 7805-7811.

24 Q. Hu, D. Vitharana, G. Y. Liu, V. Jain, M. W. Wagaman, L. Zhang, T. R. Lee and L. $\mathrm{Pu}$, Macromolecules, 1996, 29, 1082-1084.

25 Z. Liu, Y. He, B. Li, J. Liu and Q. Fan, Macromol. Rapid. Commun., 2007, 28, 2249-2255.

26 G. Koeckelberghs, T. Verbiest, M. Vangheluwe, L. De Groof, I. Asselberghs, I. Picard, K. Clays, A. Persoons and C. Samyn, Chem. Mater., 2005, 17, 118-121.

27 J. Casado, S. Hotta, V. Hernández and J. T. L. Navarrete, J. Phys. Chem. A, 1999, 103, 816-822.

28 J. Casado, H. E. Katz, V. Hernández and J. T. L. Navarrete, Vib. Spectrosc., 2002, 30, 175-189.

29 L. D. Bari, G. Pescitelli and P. Salvadori, J. Am. Chem. Soc., 1999, 121, 7998-8004.

30 I. Hanazaki and H. Akimoto, J. Am. Chem. Soc., 1972, 94, 4102-4106.

31 H. J. Deussen, E. Hendrickx, C. Boutton, D. Krog, K. Clays, K. Bechgaard, A. Persoons and T. Bjørnholm, J. Am. Chem. Soc., 1996, 118, 6841-6852.

32 M. Bandin, S. Casolari, P. G. Cozzi, G. Proni, E. Schmohel, G. P. Spada, E. Tagliavini and A. U. Ronchi, Eur. J. Org. Chem., 2000, 2000, 491-497.

33 L. D. Bari, G. Pescitelli, F. Marchetti and P. Salvadori, J. Am. Chem. Soc., 2000, 122, 6395-6398.

34 G. Gottarelli and G. P. Spada, J. Org. Chem., 1986, 51, 589-592.

35 S. F. Mason and R. H. Seal, Tetrahedron, 1974, 30, 1671-1682.

36 K. Y. Musick, Q. Hu and L. Pu, Macromolecules, 1998, 31, 2933-2942.

37 J. Pina, J. S. de Melo, H. D. Burrows, A. L. Maçanita, F. Galbrecht, T. Bünnagel and U. Scherf, Macromolecules, 2009, 42, 1710-1719.

38 I. Hoogmartens, P. Adriaensens, D. Vanderzande, J. Gelan, C. Quattrocchi, R. Lazzaroni and J. L. Brédas, Macromolecules, 1992, 25, 7347-7356.

39 S. A. Jenekhe, J. A. Osaheni, Science, 1994, 265, 765-768. 
40 J. Pomrnerehne, H. Vestweber, W. Guss, R. E. Mahrt, H. Bässler, M. Porsch and J. Daub, Adv. Mater., 1995, 7, 551-554.

41 J. L. Brédas, B. Thémans, J. G. Fripiat, J. M. André and R. R. Chance, Phys. Rev. B, 1984, 29, 6761-6773. 


\section{Graphic abstract for table of contents}

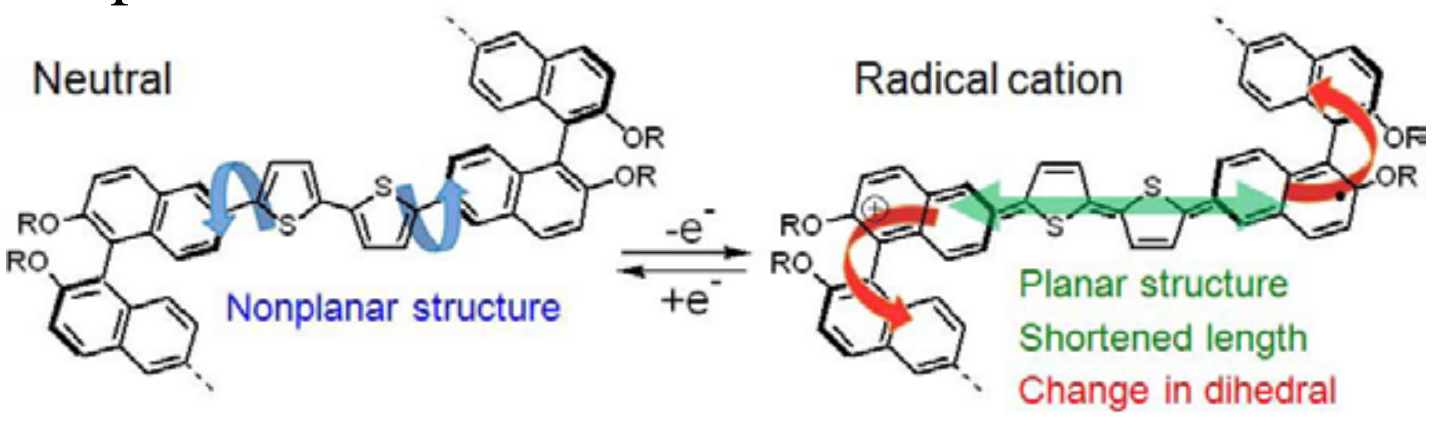

A series of axially chiral conjugated binaphthyl-thiophene copolymers were chemically and electrochemically synthesized. Chiroptical properties of the polymers were reversibly changed by an electrochemical redox process. 

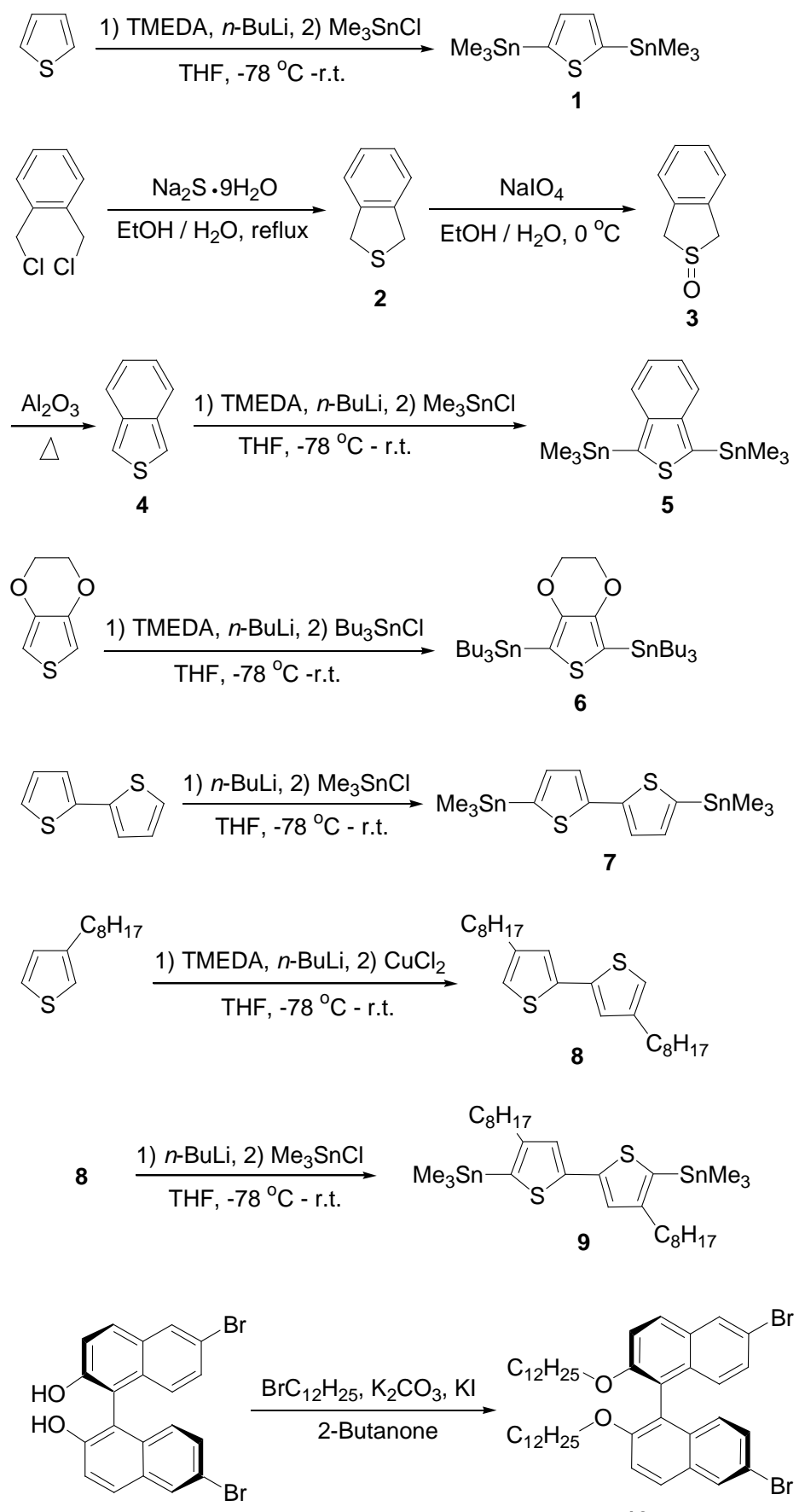

(R)-6,6'-Dibromo-1,1'-bi-2,2'-naphthol

10

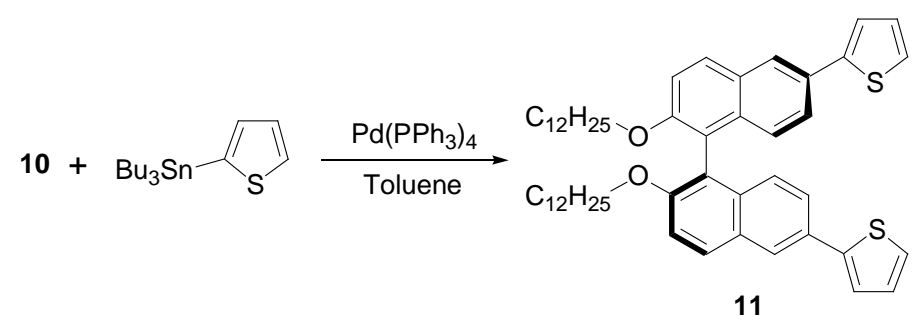

Scheme 1. Synthesis of monomers. (TMEDA; $N, N, N^{\prime}, N^{\prime}$-tetramethylethylenediamine) 
<smiles>CCCOc1ccc2cc(Br)ccc2c1-c1c(OCCC)ccc2cc(Br)ccc12</smiles>
10

$$
\text { Ar = }=
$$

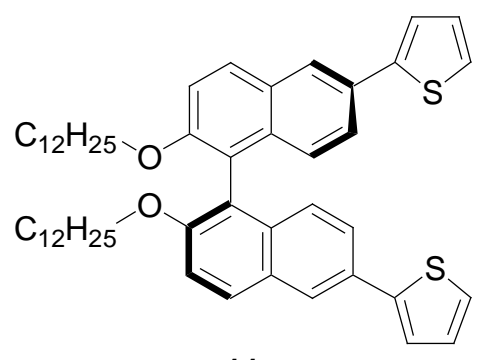

11

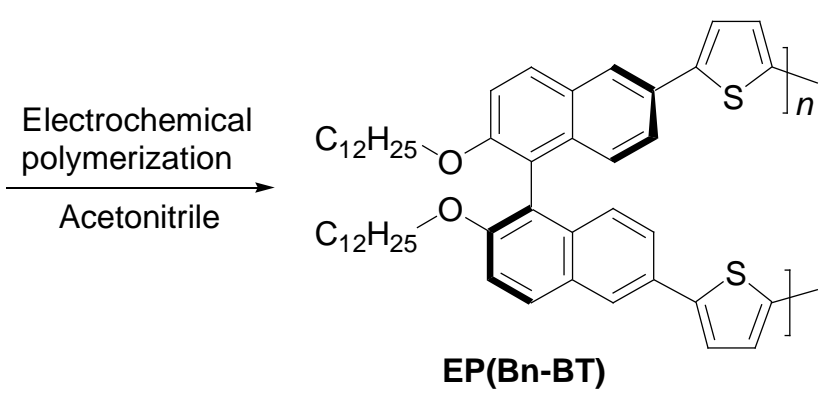

$\mathrm{EP}(\mathrm{Bn}-\mathrm{BT})$

Scheme 2. Synthesis of polymers. 
Table 1. Polymerization results.

\begin{tabular}{|c|c|c|c|c|}
\hline Polymer & $M_{\mathrm{n}}\left(\times 10^{3}\right)^{\mathrm{a}, \mathrm{b}}$ & $M_{\mathrm{w}}\left(\times 10^{3}\right)^{\mathrm{a}, \mathrm{c}}$ & $M_{\mathrm{w}} / M_{\mathrm{n}}{ }^{\mathrm{a}}$ & Yield (\%) ${ }^{\mathrm{d}}$ \\
\hline $\mathrm{P}(\mathrm{Bn}-\mathrm{T})$ & 4.2 & 5.8 & 1.4 & 54 \\
\hline $\mathrm{P}(\mathrm{Bn}-\mathrm{ITN})$ & 3.9 & 4.6 & 1.2 & 26 \\
\hline P(Bn-EDOT) & 4.4 & 5.6 & 1.3 & 49 \\
\hline $\mathrm{P}(\mathrm{Bn}-\mathrm{BT})$ & 4.8 & 7.7 & 1.6 & 27 \\
\hline $\mathrm{P}(\mathrm{Bn}-\mathrm{B} 8 \mathrm{~T})$ & 3.9 & 4.6 & 1.4 & 66 \\
\hline
\end{tabular}

a) Values against polystyrene standards.

b) Number average molecular weight.

c) Weight average molecular weight.

d) Calculated by $\left(\mathrm{W}_{\mathrm{s}} /\left(\mathrm{W}_{\mathrm{m}} \cdot \mathrm{N}_{\mathrm{m}}\right)\right)$, $\mathrm{W}_{\mathrm{s}}$ : weight of the polymer sample $(\mathrm{g}), \mathrm{W}_{\mathrm{m}}$ : weight of monomer repeating units of the polymers $(\mathrm{g} / \mathrm{mol}), \mathrm{N}_{\mathrm{m}}$ : Amount of the used monomer (mol) 


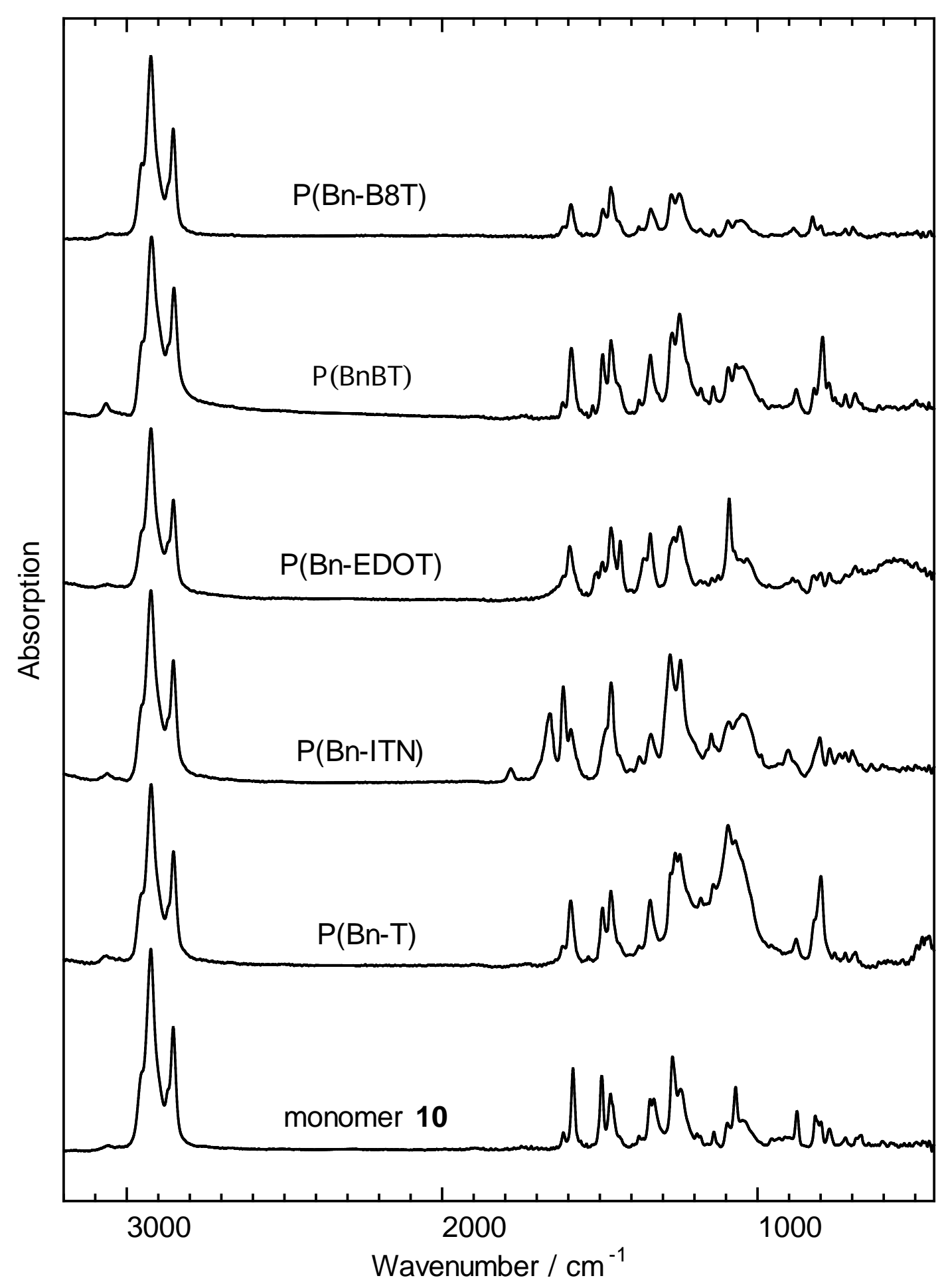

Figure 1. Infrared absorption spectra of the polymers and monomer $\mathbf{1 0}$ 

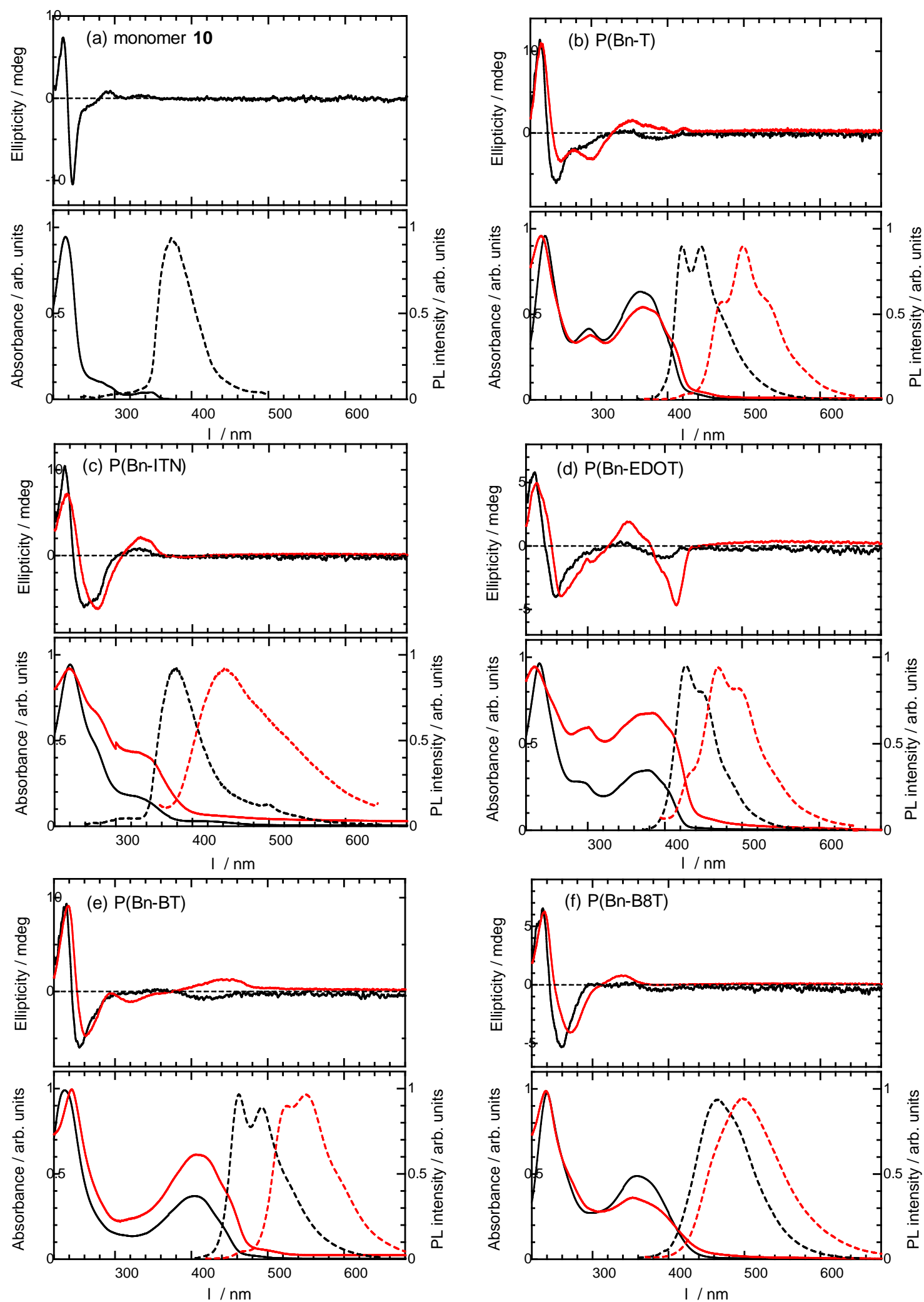

Figure 2. CD (upper), UV-vis absorption (solid), and photoluminescence (dashed) spectra of the polymers in THF solution (black) and in film (red) states. 
Table 2. Maximum absorption wavelengths $\left(\lambda_{\max }\right)$, absorption onset wavelengths $\left(\lambda_{\text {onset }}\right)$, and maximum emission wavelength $\left(\lambda_{\mathrm{em}}\right)$ of the polymers in THF solution and in the film state.

\begin{tabular}{|c|c|c|c|c|c|c|}
\hline Polymer & $\begin{array}{c}\lambda_{\max } \\
(\mathrm{nm})\end{array}$ & $\begin{array}{l}\lambda_{\text {onset }} \\
\text { (nm) }\end{array}$ & $\begin{array}{c}\lambda_{\text {max }, \text { film }} \\
(\mathrm{nm})\end{array}$ & $\begin{array}{l}\lambda_{\text {onset,film }} \\
\text { (nm) }\end{array}$ & $\begin{array}{c}\lambda_{\mathrm{em}} \\
(\mathrm{nm})\end{array}$ & $\begin{array}{c}\lambda_{\text {em,film }} \\
\text { (nm) }\end{array}$ \\
\hline \multirow{3}{*}{$\mathrm{P}(\mathrm{Bn}-\mathrm{T})$} & 239 & 424 & 234 & 429 & 419 & $470(\mathrm{sh})^{\mathrm{b}}$ \\
\hline & 297 & & 299 & & 444 & 499 \\
\hline & 364 & & 367 & & & \\
\hline \multirow{3}{*}{$\mathrm{P}(\mathrm{Bn}-\mathrm{ITN})$} & 240 & 482 & 240 & 392 & 377 & 442 \\
\hline & $341(\mathrm{sh})^{\mathrm{a}}$ & & $336(\mathrm{sh})^{\mathrm{a}}$ & & & \\
\hline & 409 & & & & & \\
\hline \multirow[t]{3}{*}{$\mathrm{P}(\mathrm{Bn}-\mathrm{EDOT})$} & 237 & 426 & 230 & 438 & 427 & 469 \\
\hline & 285 & & 300 & & $448(\mathrm{sh})^{\mathrm{b}}$ & $496(\mathrm{sh})^{\mathrm{b}}$ \\
\hline & 377 & & 384 & & & \\
\hline \multirow[t]{2}{*}{$\mathrm{P}(\mathrm{Bn}-\mathrm{BT})$} & 234 & 463 & 243 & 472 & 462 & 525 \\
\hline & 404 & & 408 & & 492 & 550 \\
\hline \multirow[t]{2}{*}{$\mathrm{P}(\mathrm{Bn}-\mathrm{B} 8 \mathrm{~T})$} & 240 & 428 & 238 & 438 & 465 & 498 \\
\hline & 359 & & 353 & & & \\
\hline
\end{tabular}

a) Absorption shoulder.

b) Emission shoulder 


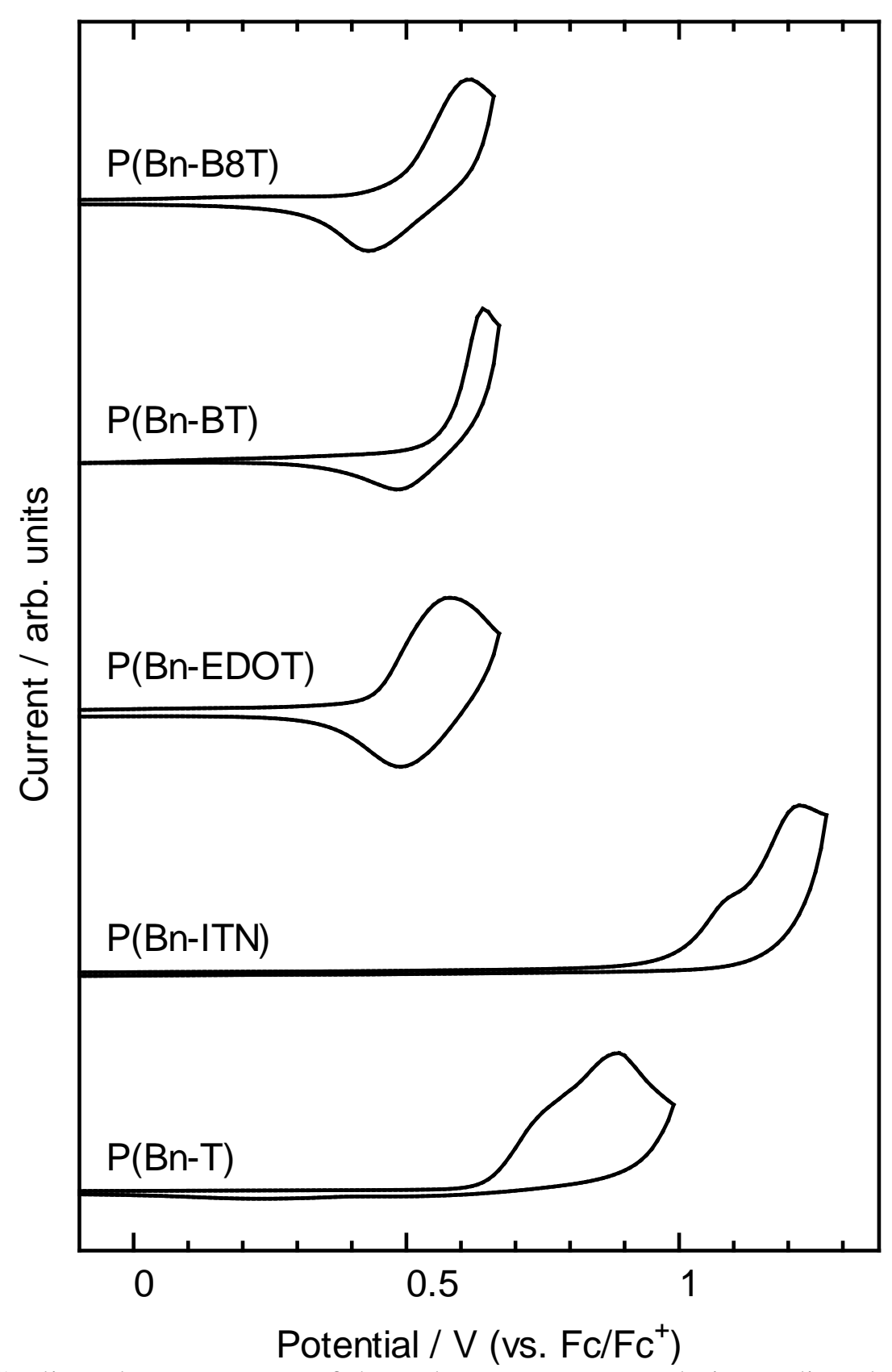

Figure 3. Cyclic voltammograms of the polymers cast on a platinum disc electrode. (0.1 $\mathrm{M}$ TBAP in acetonitrile solution with a scan rate of $100 \mathrm{mVs}^{-1}$ ). 
Table 3. Oxidation potentials $\left(E_{\text {onset,ox }}\right)$ (vs. $\left.\mathrm{Fc} / \mathrm{Fc}^{+}\right)$, maximum absorption wavelength $\left(\lambda_{\max }\right)$ in the THF solutions and onset wavelength $\left(\lambda_{\text {onset }}\right)$ of optical absorption, HOMO and LUMO values and the energy gaps $(\Delta E)$ determined from the results of cyclic voltammetry and optical absorption spectra of the polymers.

\begin{tabular}{lcccc}
\hline \multicolumn{1}{c}{ Polymer } & $\begin{array}{c}E_{\text {onset,ox }^{\mathrm{a}}} \\
(\mathrm{V})\end{array}$ & $\begin{array}{c}E_{\mathrm{HOMO}} \\
(\mathrm{eV})\end{array}$ & $\begin{array}{c}\Delta E_{\text {opt }}^{\mathrm{c}} \\
(\mathrm{eV})\end{array}$ & $\begin{array}{c}E_{\mathrm{LUMO}}{ }^{\mathrm{d}} \\
(\mathrm{eV})\end{array}$ \\
\hline $\mathrm{P}(\mathrm{Bn}-\mathrm{T})$ & $0.65 \mathrm{~V}$ & -5.45 & 2.89 & -2.56 \\
$\mathrm{P}(\mathrm{Bn}-\mathrm{ITN})$ & $0.98 \mathrm{~V}$ & -5.78 & 3.16 & -2.62 \\
$\mathrm{P}(\mathrm{Bn}-\mathrm{EDOT})$ & $0.44 \mathrm{~V}$ & -5.24 & 2.83 & -2.41 \\
$\mathrm{P}(\mathrm{Bn}-\mathrm{BT})$ & $0.57 \mathrm{~V}$ & -5.37 & 2.63 & -2.74 \\
$\mathrm{P}(\mathrm{Bn}-\mathrm{B} 8 \mathrm{~T})$ & $0.49 \mathrm{~V}$ & -5.29 & 2.83 & -2.46 \\
\hline
\end{tabular}

a) Onset oxidation potentials of the polymers calibrated by ferrocene.

b) The values were calculated from the onset oxidation potentials of the polymers with respect to $\mathrm{Fc} / \mathrm{Fc}^{+}$under the assumption that the $\mathrm{Fc} / \mathrm{Fc}^{+}$redox potential is $4.8 \mathrm{eV}$ below the vacuum level.

c) Calculated from the onset wavelength of optical absorption of the polymers.

d) Calculated from optical bandgap energy and onset oxidation potential of the polymers.

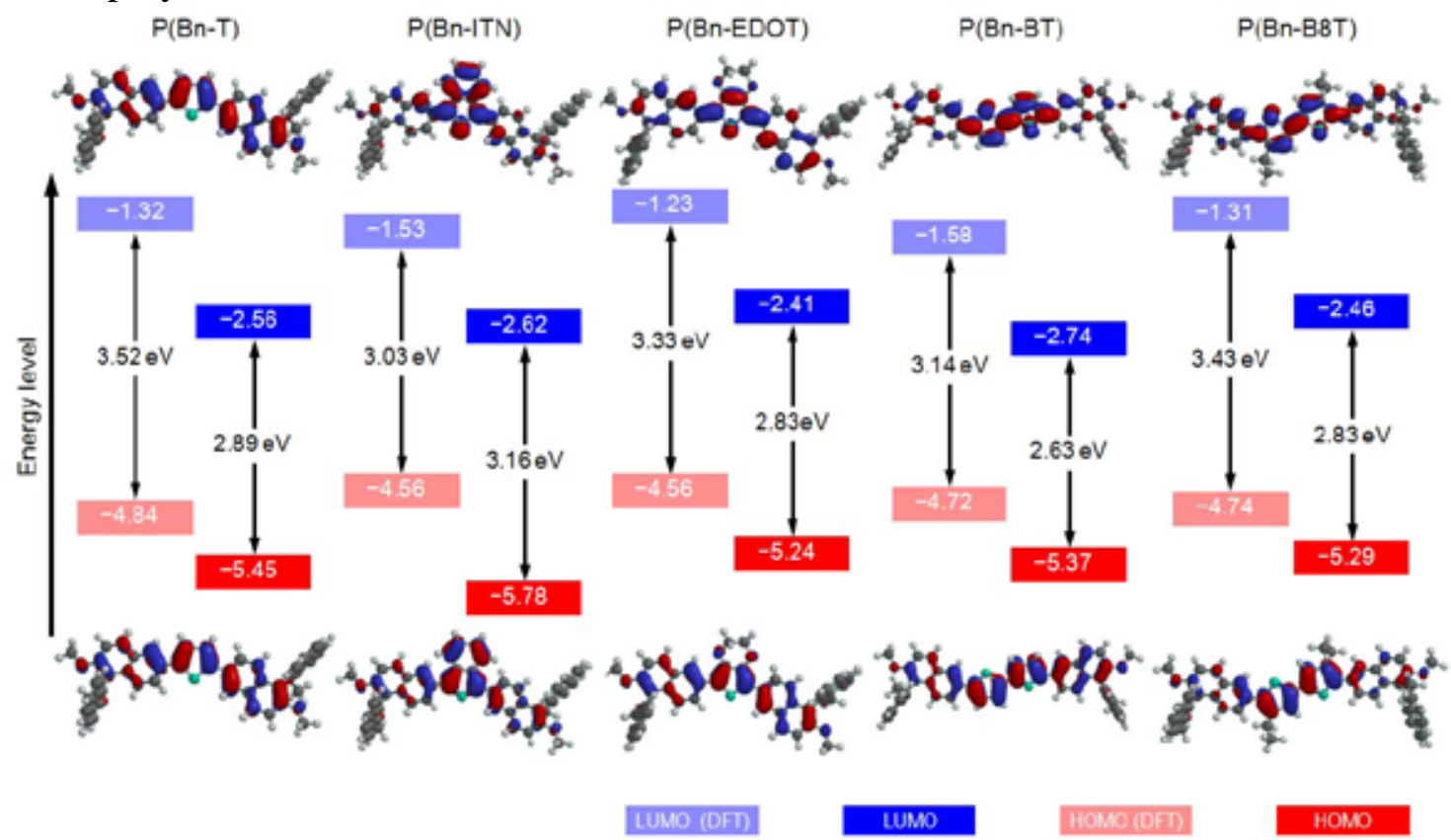

Figure 4. HOMO and LUMO and their energy levels of model compounds calculated by DFT method and those of the polymers in the film state estimated from observed oxidation potentials and optical band gaps. 


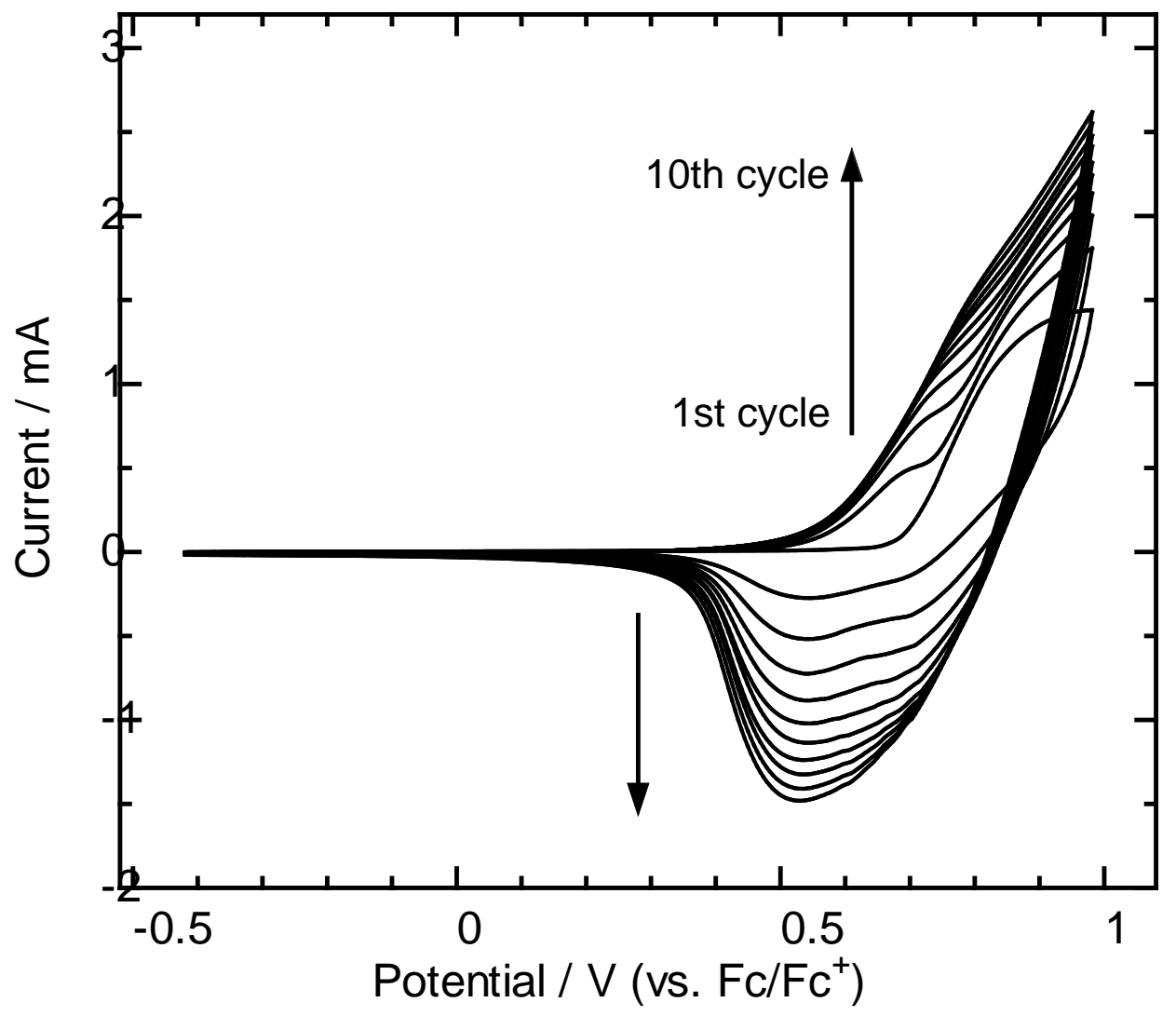

Figure 5. Cyclic voltammograms for electrochemical polymerization of $\mathbf{1 1}$ in $0.1 \mathrm{M}$ TBAP acetonitrile solution using an $\mathrm{Ag} / \mathrm{Ag}^{+}$reference electrode with a scan rate of 100 $\mathrm{mVs}^{-1}$. 


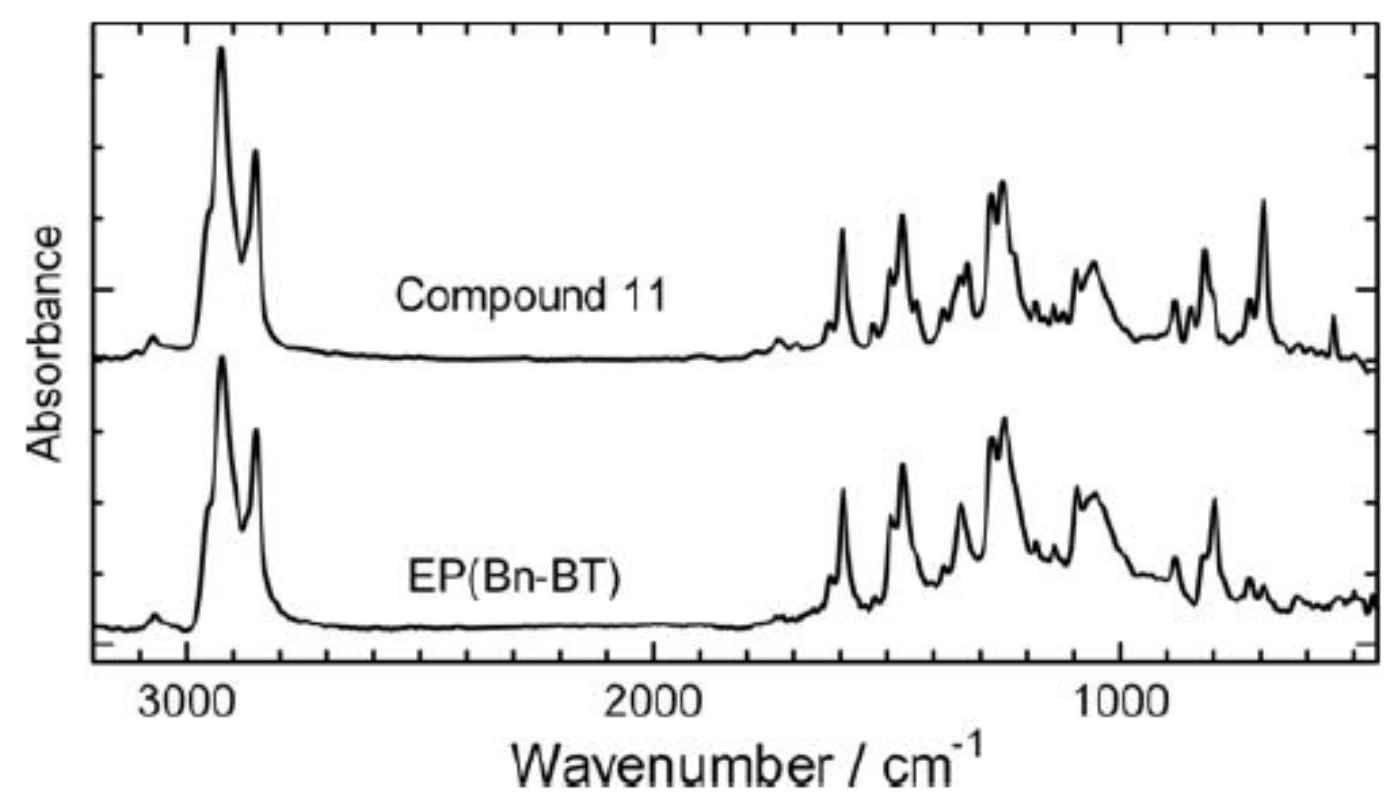

Figure 6. IR absorption spectra of $\mathbf{1 1}$ and EP(Bn-BT). 


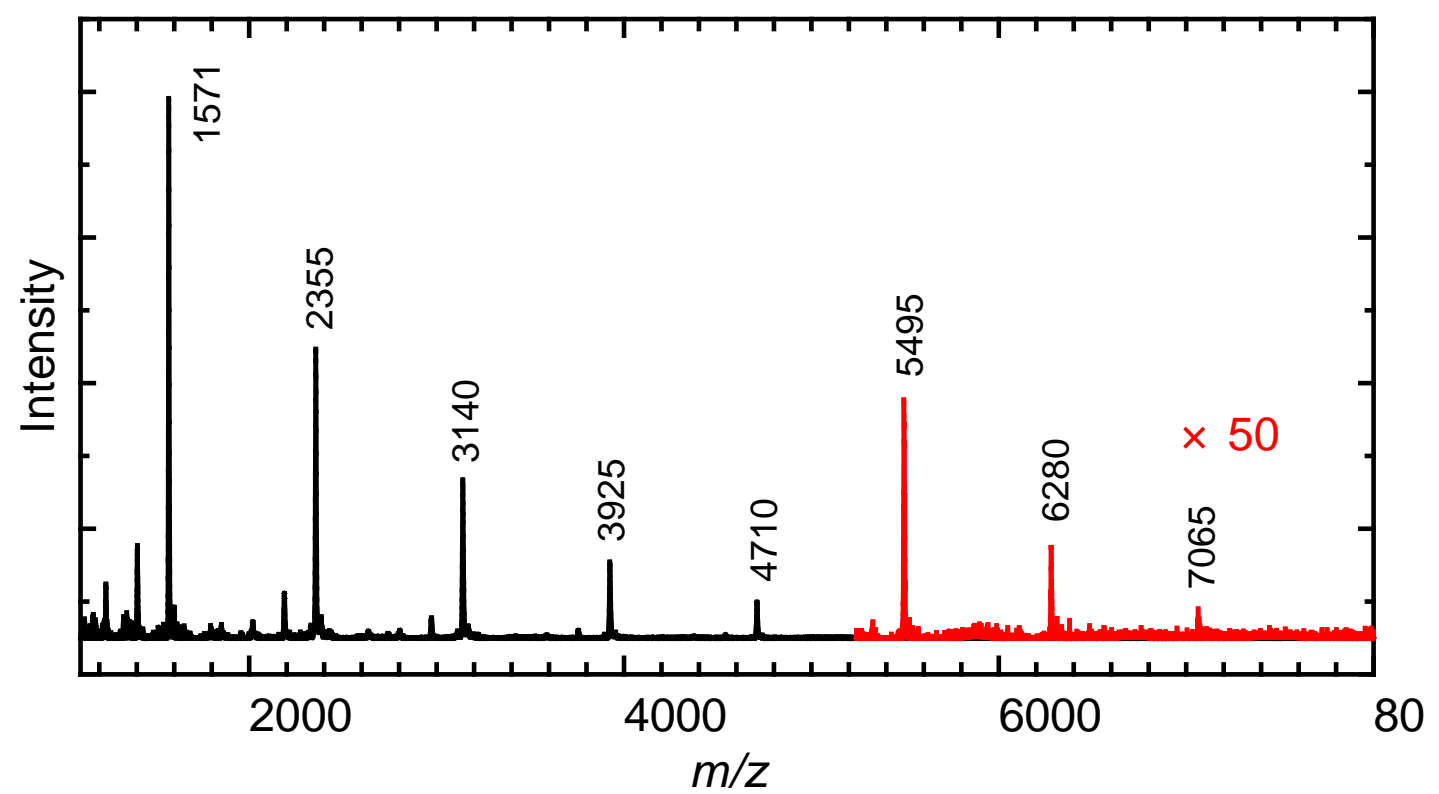

Figure 7. MALDI-TOF-MS spectrum of EP(Bn-BT). 


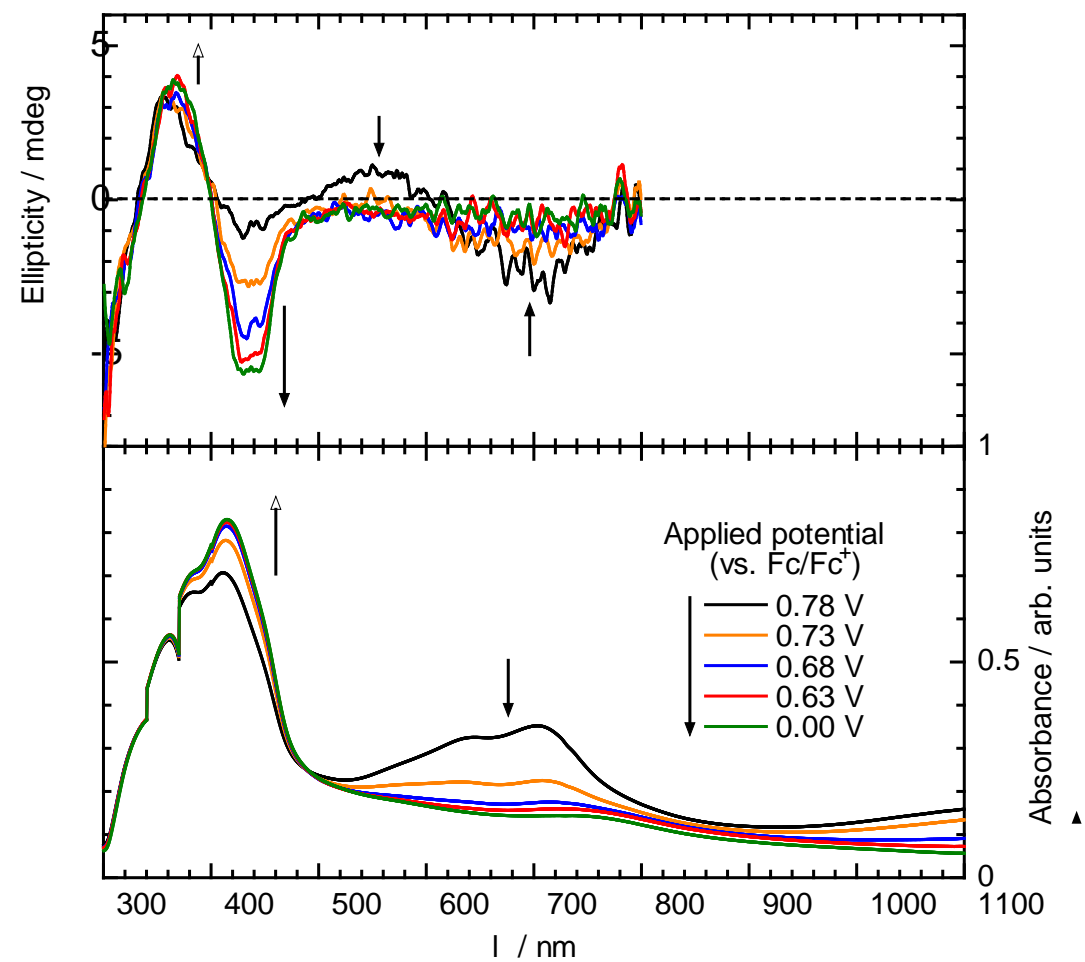

Figure 8. CD and UV-vis spectra of $\mathrm{EP}(\mathrm{Bn}-\mathrm{BT})$ at various applied potentials during oxidation (top) and reduction (bottom) process. 
(a) Neutral state

Top view

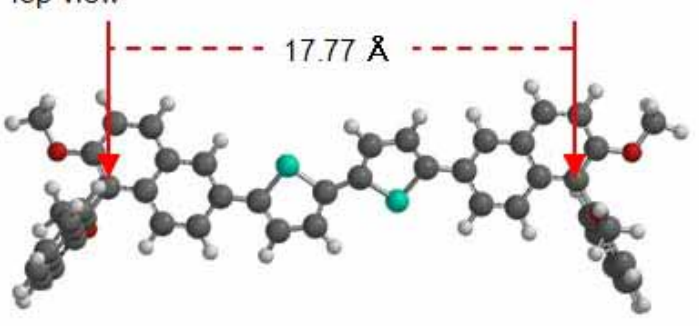

Side view

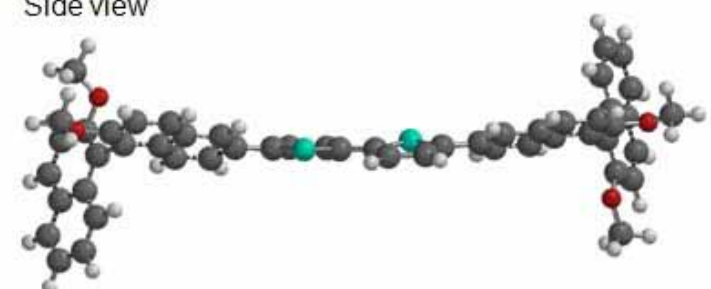

(b) Radical cationic state

Top view

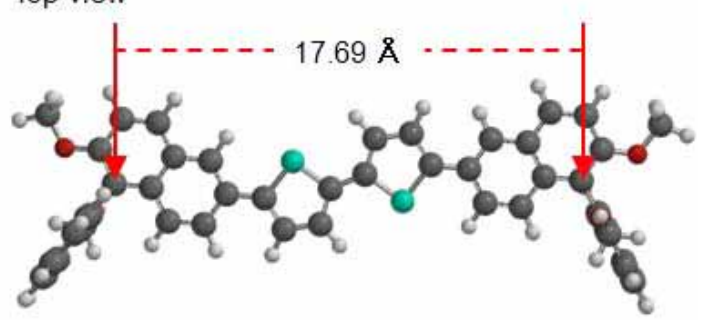

Side view

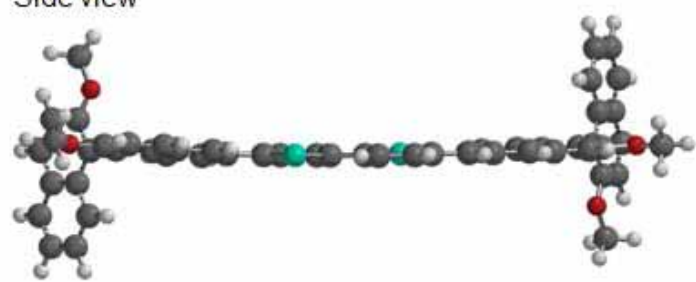

Figure 9. Optimized geometries of model compound for $\mathrm{P}(\mathrm{Bn}-\mathrm{BT})$ in neutral state (a), and radical cationic state (b).

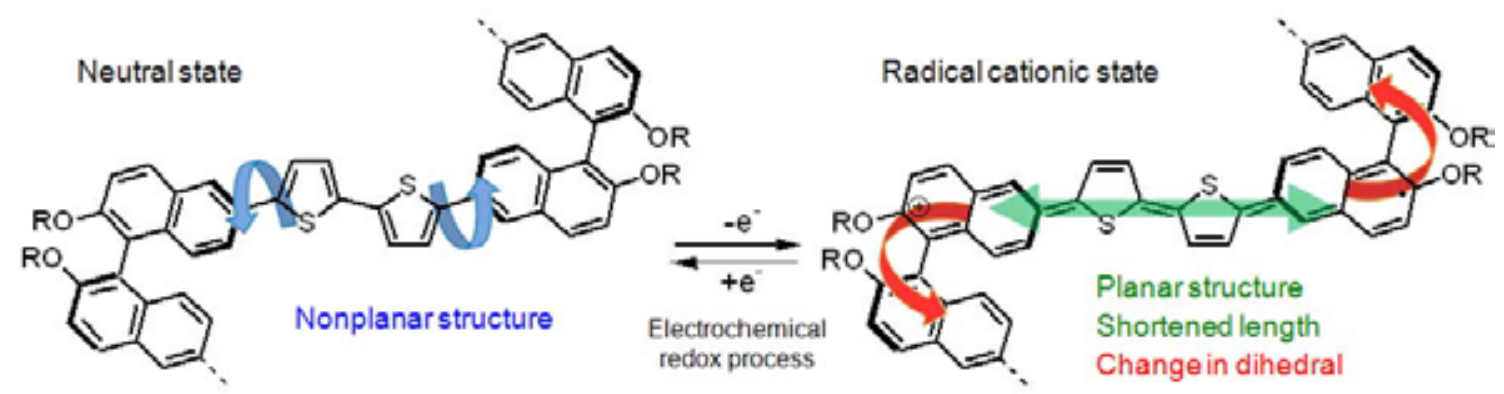

Figure 10. Possible mechanism of structural change of the EP(Bn-BT) in the film by electrochemical redox process. 
Electronically Supplementary Information for:

Synthesis and Optical Properties of 1,1-Binaphthyl-Thiophene Alternating Copolymers with Main Chain Chirality

Kohsuke Kawabata and Hiromasa Goto*

Division of Materials Science, Faculty of Pure and Applied Sciences, University of Tsukuba, Tsukuba, Ibaraki, 305-8573, Japan

*Correspondence to H. Goto, e-mail: gotoh@ims.tsukuba.ac.jp Fax: +81-298-53-4490 


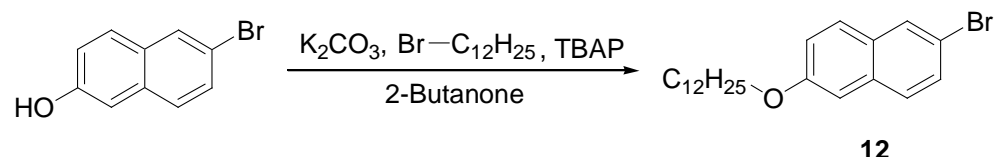

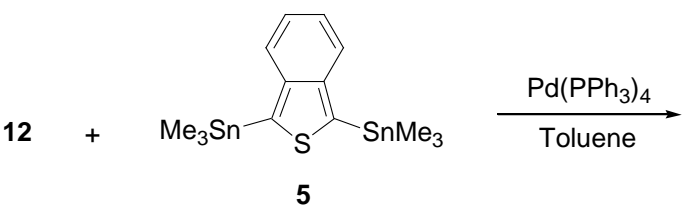

5

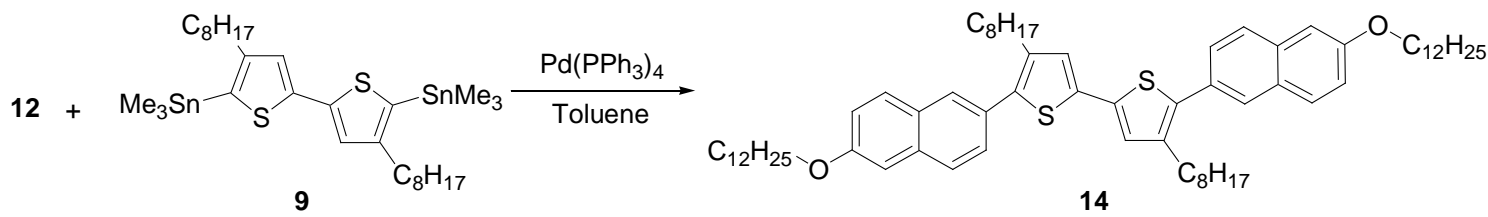

Scheme S1. Synthesis of model compounds.

\section{2-Bromo-6-dodecyloxy-naphthalene (12)}

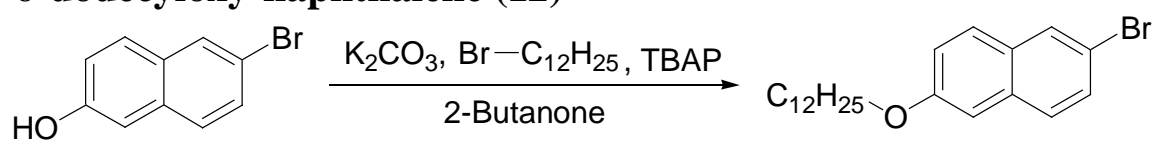

\section{Scheme S2}

6-bromonaphthol (1.12 g, $5.0 \mathrm{mmol})$, potassium carbonate $(0.83 \mathrm{~g}, 6.0 \mathrm{mmol})$, 1-bromododecane $(1.50 \mathrm{~g}, 6.0 \mathrm{mmol})$, and TBAP (0.085 g, $0.25 \mathrm{mmol}$ ) were mixed in $10 \mathrm{~mL}$ of 2-butanone and refluxed at $80{ }^{\circ} \mathrm{C}$ for 24 hours. After evaporation of the solvent, the residue was extracted with dichloromethane, and dried over magnesium sulfate. Recrystallization from ethanol to afford white solid (1.72 g, $4.4 \mathrm{mmol}$, yield = 88\%). ${ }^{1} \mathrm{H}$ NMR ( $400 \mathrm{MHz}$; $\mathrm{CDCl}_{3}$; TMS) $\delta 0.88$ (t, 3H, -CH,$J=6.8 \mathrm{~Hz}$ ), $1.27-1.37$ (m, $16 \mathrm{H},-\mathrm{C}_{8} \mathrm{H}_{16}-\mathrm{CH}_{3}$ ), 1.49 (quintet, $2 \mathrm{H},-\mathrm{CH}_{2}-\mathrm{C}_{9} \mathrm{H}_{19}, J=7.3 \mathrm{~Hz}$ ), 1.84 (quintet, $2 \mathrm{H}$, $\left.-\mathrm{CH}_{2}-\mathrm{C}_{10} \mathrm{H}_{21}, J=7.0 \mathrm{~Hz}\right), 4.05\left(\mathrm{t}, 2 \mathrm{H}, \mathrm{O}-\mathrm{CH}_{2}-\mathrm{C}_{11} \mathrm{H}_{23}, J=6.8 \mathrm{~Hz}\right), 7.08(\mathrm{~d}, 1 \mathrm{H}$, $5 H$-(naphthalene), $J=2.4 \mathrm{~Hz}$ ), 7.16 (dd, $1 \mathrm{H}, 7 \mathrm{H}$-(naphthalene), $J=2.6 \mathrm{~Hz}$ ), 7.48 (dd, $1 \mathrm{H}, 3 H$-(naphthalene), $J=1.8 \mathrm{~Hz}$ ), 7.58 (d, 1H, $4 H$-(naphthalene), $J=8.8 \mathrm{~Hz}$ ), 7.63 (d, $1 \mathrm{H}, 8 \mathrm{H}$-(naphthalene), $J=8.8 \mathrm{~Hz}), 7.90(\mathrm{~d}, 1 \mathrm{H}, 1 \mathrm{H}$-(naphthalene), $J=2.0 \mathrm{~Hz}) .{ }^{13} \mathrm{C}(100$ MHz; CDCl 3 ; TMS) $\delta$ 14.14, 22.70, 26.10, 29.20, 29.37, 29.41, 29.60, 29.61, 29.64, 29,67, 31.92, 68.10, 106.47, 116.86. 120.09, 128.33, 128.40, 129.52, 129.62, 129.90, $133.09,157.42$.

\section{1,3-Bis-(6-dodecyloxy-naphthalen-2-yl)-isothianaphthene (13)}

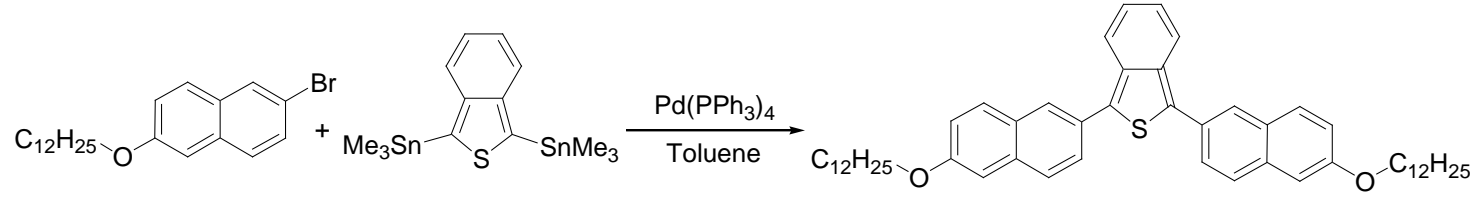

Scheme S3

A solution 1,3-bis-trimethylstannanyl-isothianaphethene $(0.138 \mathrm{~g}, \quad 0.30 \mathrm{mmol})$, 2-Bromo-6-dodecyloxy-naphthalene (0.247, $0.63 \mathrm{mmol})$, and $\mathrm{Pd}\left(\mathrm{PPh}_{3}\right)_{4}(0.007 \mathrm{~g}, 0.006$ 
mmol) in toluene ( $2 \mathrm{~mL}$ ) were refluxed at $90{ }^{\circ} \mathrm{C}$ for 24 hours. After cooling to room temperature, the mixture was purified silica gel column chromatography (contain 10 $\mathrm{v} / \mathrm{v} \%$ of potassium carbonate) (eluent: hexane/chloroform $=7 / 3$ ) to afford an orange solid ( $0.116 \mathrm{~g}, 0.15 \mathrm{mmol}$, yield $=51 \%) .{ }^{1} \mathrm{H} \mathrm{NMR}\left(400 \mathrm{MHz}\right.$; $\mathrm{CDCl}_{3}$; TMS) $\delta 0.88$ (t, $\left.6 \mathrm{H},-\mathrm{CH}_{3}, J=7.0 \mathrm{~Hz}\right), 1.28-1.41\left(\mathrm{~m}, 32 \mathrm{H},-\mathrm{O}-\mathrm{C}_{3} \mathrm{H}_{6}-\mathrm{C}_{8} \mathrm{H}_{16}-\mathrm{CH}_{3}\right), 1.49-1.54(\mathrm{~m}, 4 \mathrm{H}$, $-\mathrm{O}-\mathrm{C}_{2} \mathrm{H}_{4}-\mathrm{CH}_{2}-\mathrm{C}_{9} \mathrm{H}_{19}$ ), 1.87 (quintet, $4 \mathrm{H},-\mathrm{O}-\mathrm{CH}_{2}-\mathrm{CH}_{2}-\mathrm{C}_{10} \mathrm{H}_{21}, J=7.1 \mathrm{~Hz}$ ), 4.11 (t, $4 \mathrm{H}$, -O-CH $2^{-}, J=6.6 \mathrm{~Hz}$ ), 7.13 (dd, 2H, 5,6- $\mathrm{H}$-(isothianaphthene), $J=3.2,6.8 \mathrm{~Hz}$ ), 7.18 (d, $2 \mathrm{H}, 5 \mathrm{H}$-(naphthalene), $J=2.4 \mathrm{~Hz}$ ), 7.21 (dd, $2 \mathrm{H}, 7 \mathrm{H}$-(naphthalene), $J=2.2,8.6 \mathrm{~Hz}$ ), 7.79 - 7.85 (m, 6H, 3,4,7-H-(naphthalene)), 7.93 (dd, 2H, 4,7- $\mathrm{H}$-(isothianaphthene), $J=$ 3.2, $6.8 \mathrm{~Hz}$ ), 8.08 (s, $2 \mathrm{H}, 1 \mathrm{H}$-(naphthalene)). ${ }^{13} \mathrm{C}(100 \mathrm{MHz}$; CDCl 3 ; TMS) $\delta 14.14$, 22.70, 26.13, 29.25, 29.37, 29.45, 29.61, 29.63, 29.66, 29.69, 31.93, 68.14, 106.53, $119.78,121.36,124.20,127.41,127.61,127.88,129.13,129.52,133.87,134.42,135.27$, 157.51.

\section{5,5'-Bis-(6-dodecyloxy-naphthalen-2-yl)-4,4'-dioctyl-[2,2']bithiophenyl (14)}

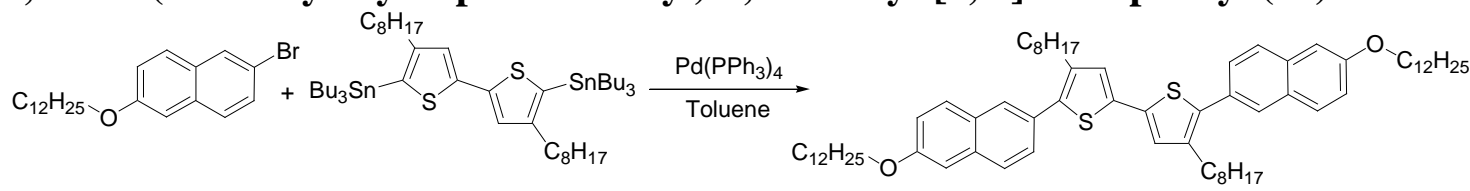

Scheme S4

A solution 4,4'-Dioctyl-5,5'-bistrimethylstannyl-2,2'-bithiophene (0.215 g, $0.30 \mathrm{mmol})$, 2-Bromo-6-dodecyloxy-naphthalene $(0.247,0.63 \mathrm{mmol})$, and $\mathrm{Pd}\left(\mathrm{PPh}_{3}\right)_{4}(0.007 \mathrm{~g}, 0.006$ mmol) in toluene ( $2 \mathrm{~mL}$ ) were refluxed at $90{ }^{\circ} \mathrm{C}$ for 24 hours. After cooling to room temperature, the mixture was purified silica gel column chromatography (contain 10 $\mathrm{v} / \mathrm{v} \%$ of potassium carbonate) (eluent: hexane/dichloromethane $=8 / 2$ ) to afford a yellow solid (0.120 g, $0.12 \mathrm{mmol}$, yield $=40 \%) .{ }^{1} \mathrm{H}$ NMR (400 MHz; $\mathrm{CDCl}_{3}$; TMS) $\delta 0.84-$ $0.90\left(\mathrm{~m}, \quad 12 \mathrm{H}, \quad-\mathrm{CH}_{3}\right), 1.23-1.37$ (m, 52H, (Thophene) $-\mathrm{C}_{2} \mathrm{H}_{4}-\mathrm{C}_{5} \mathrm{H}_{10}-\mathrm{CH}_{3}$, $\left.-\mathrm{O}-\mathrm{C}_{3} \mathrm{H}_{6}-\mathrm{C}_{8} \mathrm{H}_{16}-\mathrm{CH}_{3}\right), 1.47-1.53\left(\mathrm{~m}, 4 \mathrm{H},-\mathrm{O}-\mathrm{C}_{2} \mathrm{H}_{4}-\mathrm{CH}_{2}-\mathrm{C}_{9} \mathrm{H}_{19}\right), 1.66$ (quintet, $4 \mathrm{H}$, (Thophene) $-\mathrm{CH}_{2}-\mathrm{CH}_{2}-\mathrm{C}_{6} \mathrm{H}_{13}, J=7.5 \mathrm{~Hz}$ ), 1.86 (quintet, $4 \mathrm{H}$, $-\mathrm{O}-\mathrm{CH}_{2}-\mathrm{CH}_{2}-\mathrm{C}_{10} \mathrm{H}_{21}, J=$ $7.0 \mathrm{~Hz}$ ), 2.69 (t, 4H, (Thophene)- $\mathrm{CH}_{2}, J=8.0 \mathrm{~Hz}$ ), 4.09 (t, 4H, -O-CH $\mathrm{C}^{-}, J=6.6 \mathrm{~Hz}$ ), 7.10 (s, 2H, 3,3'H-(bithiophene)), 7.15 (d, 2H, 5H-(naphthalene), $J=2.4 \mathrm{~Hz}$ ), 7.18 (dd, 2H, $7 H$-(naphthalene), $J=2.6,9.0 \mathrm{~Hz}$ ), 7.54 (dd, $2 \mathrm{H}, 3 H$-(naphthalene), $J=1.8,8.2 \mathrm{~Hz}$ ), 7.74 - 7.76 (m, 4H, 4,7- $H$-(naphthalene)), 7.83 (d, $2 \mathrm{H}, 1 H$-(naphthalene), $J=1.2 \mathrm{~Hz}$ ). ${ }^{13} \mathrm{C}\left(100 \mathrm{MHz}\right.$; $\mathrm{CDCl}_{3}$; TMS) $\delta$ 14.12, 14.14, 22.66, 22.70, 26.13, 28.90, 29.25, 29.38, 29.44, 29.49, 29.62, 29.65, 29.68, 30.92, 31.87, 31.93, 68.12, 106.42, 119.61, 125.91, 126.86, 127.77, 128 74, 129.49, 129.55, 133.71, 135.47, 136.83, 139.47, 157.46. 


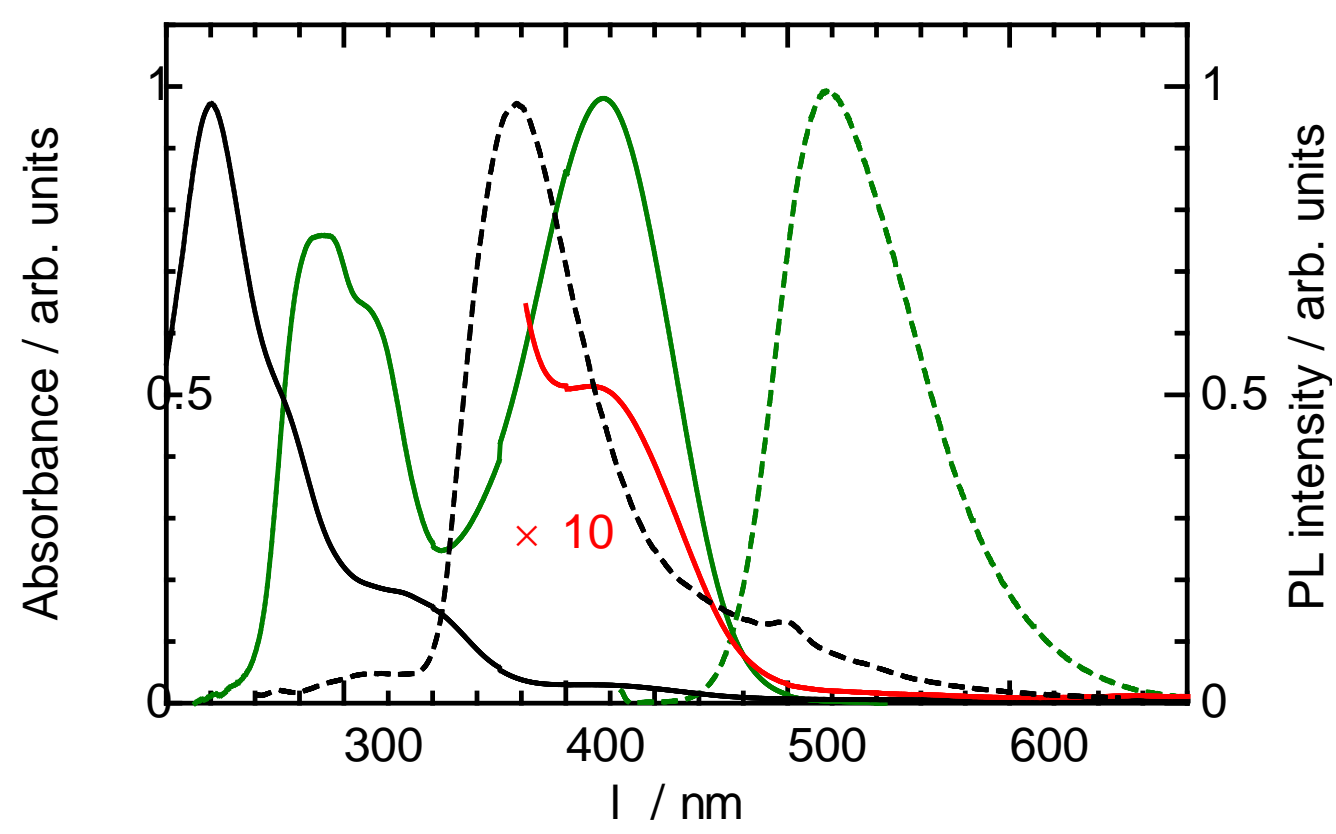

Figure S1. UV-vis absorption (solid) and PL (dashed) spectra of P(Bn-ITN) (black and red $(\times 10)$ ) and compound 13 (green) in THF.

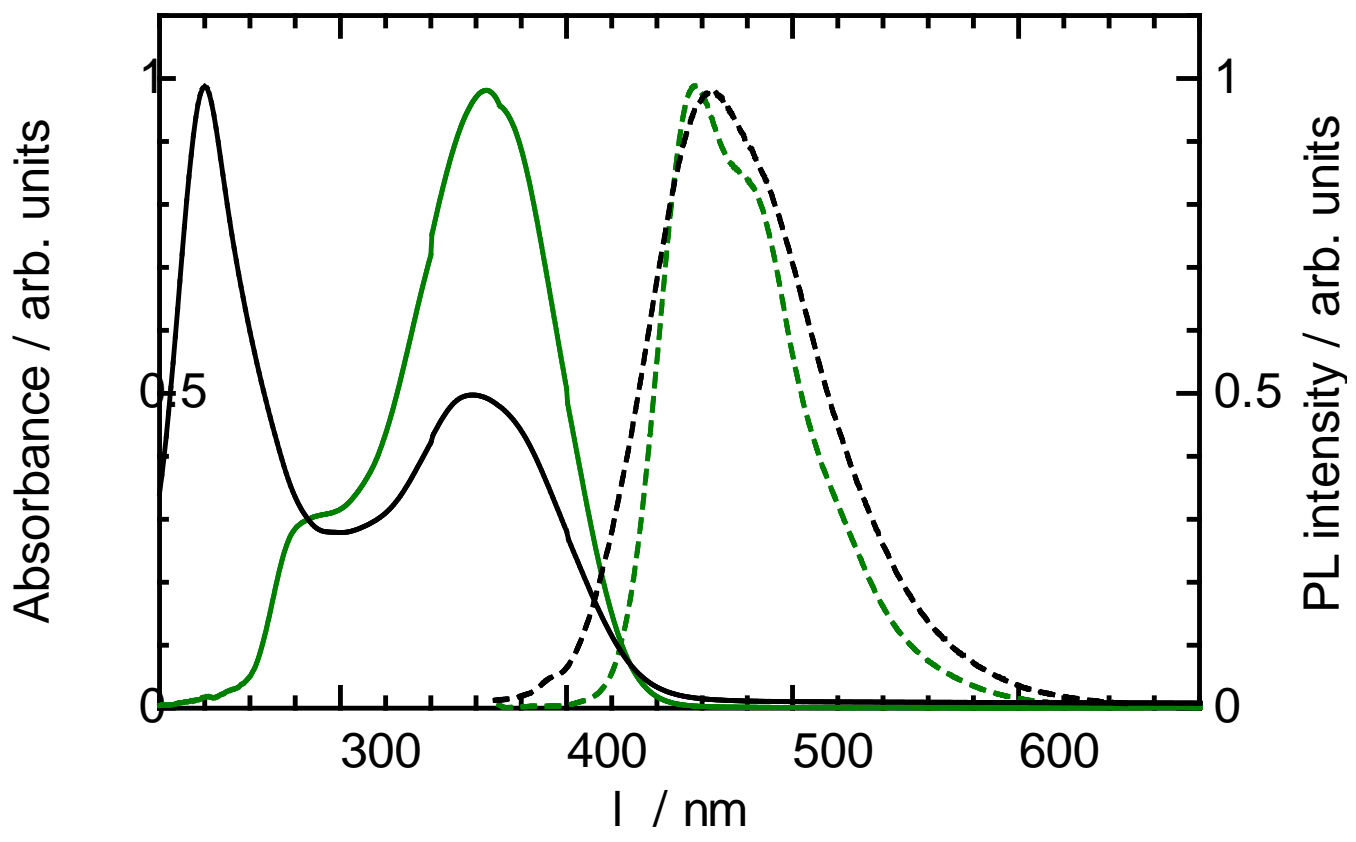

Figure S2. UV-vis absorption (solid) and PL (dashed) spectra of P(Bn-B8T) (black) and compound 14 (green) in THF. 


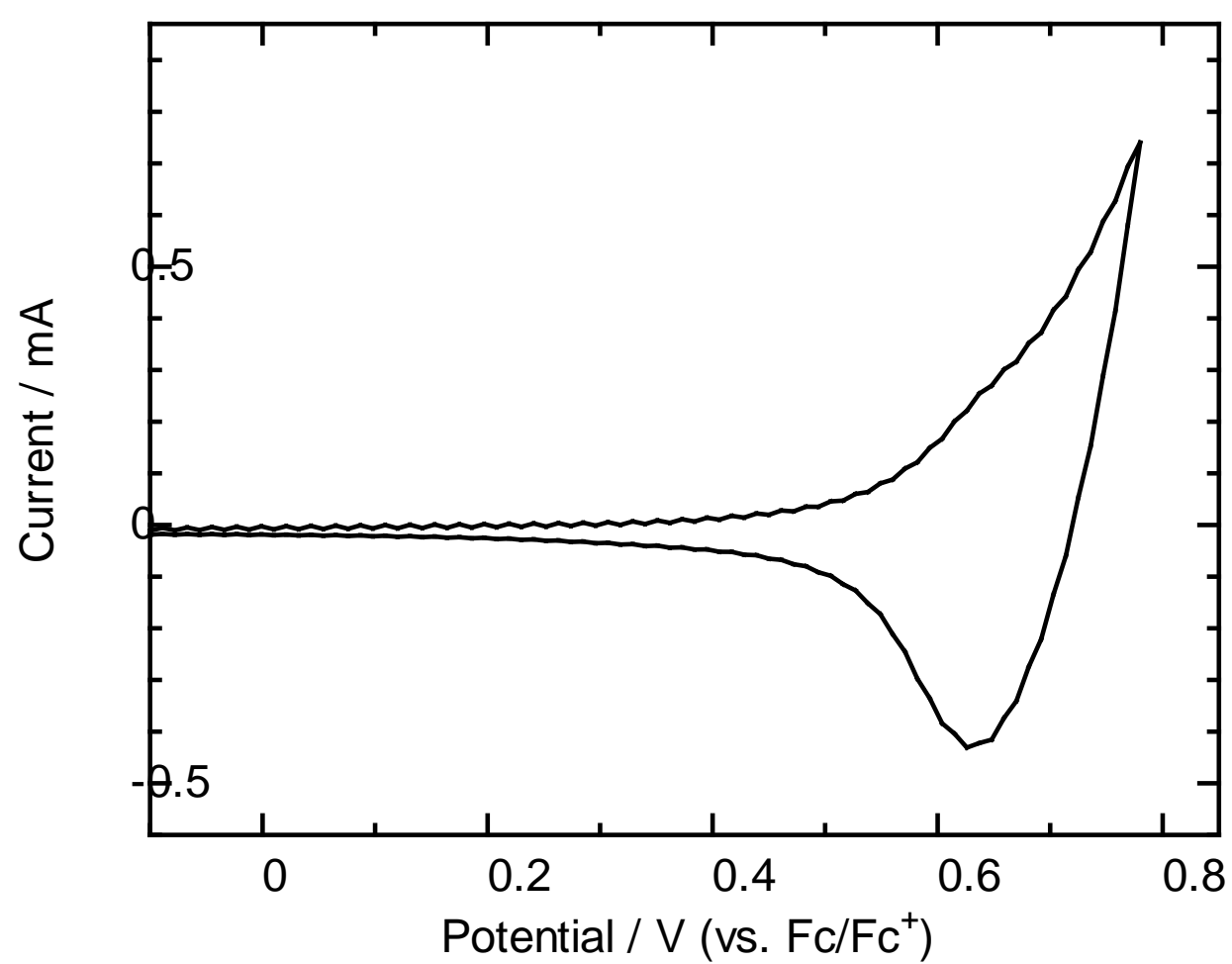

Figure S3. A cyclic voltammogram of EP(Bn-BT) on deposited an ITO glass electrode at a scan rate of $100 \mathrm{mVs}^{-1}$.

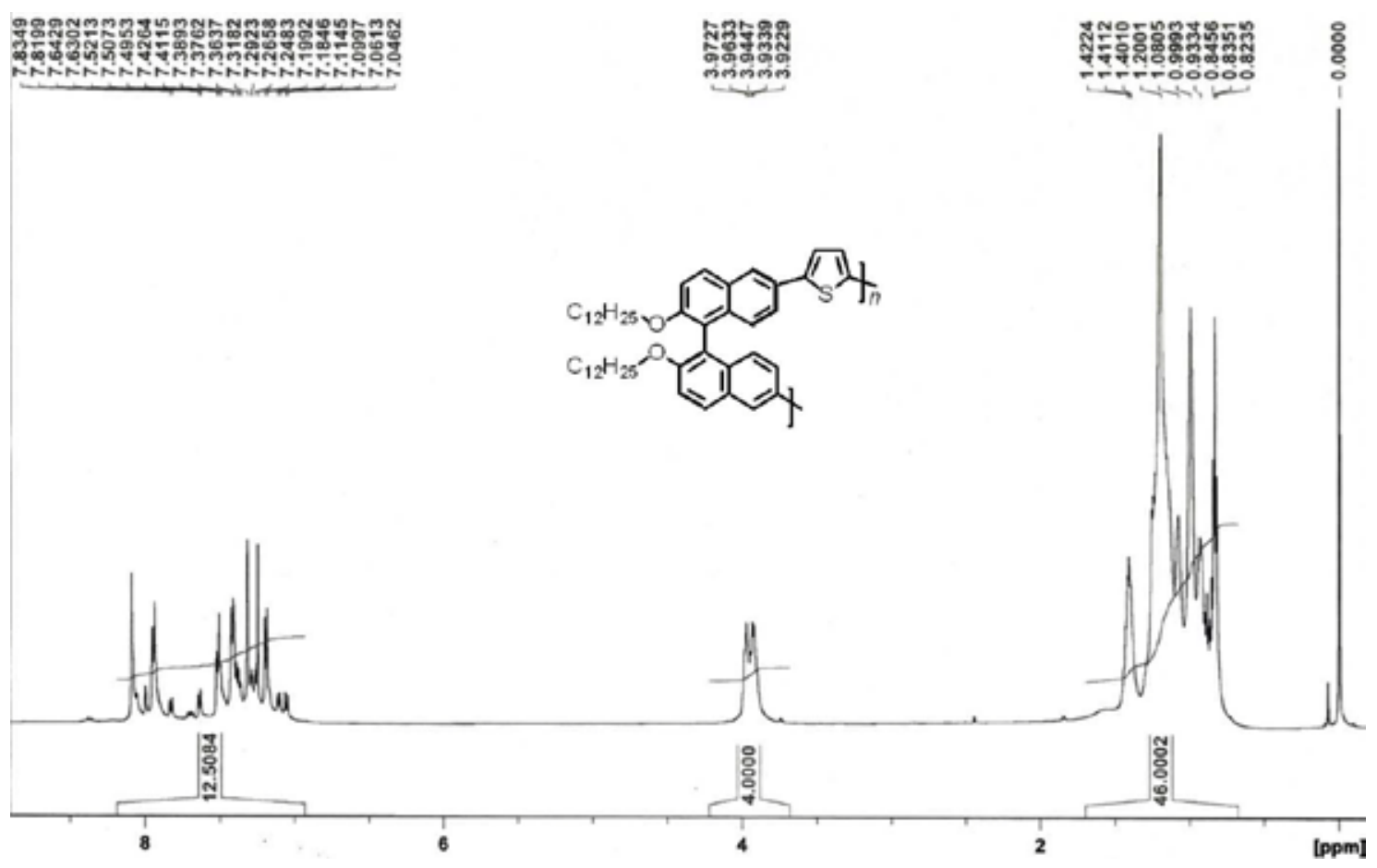

Figure S4. ${ }^{1} \mathrm{H}$ NMR spectrum $(600 \mathrm{MHz})$ of $\mathrm{P}(\mathrm{Bn}-\mathrm{T})$. 


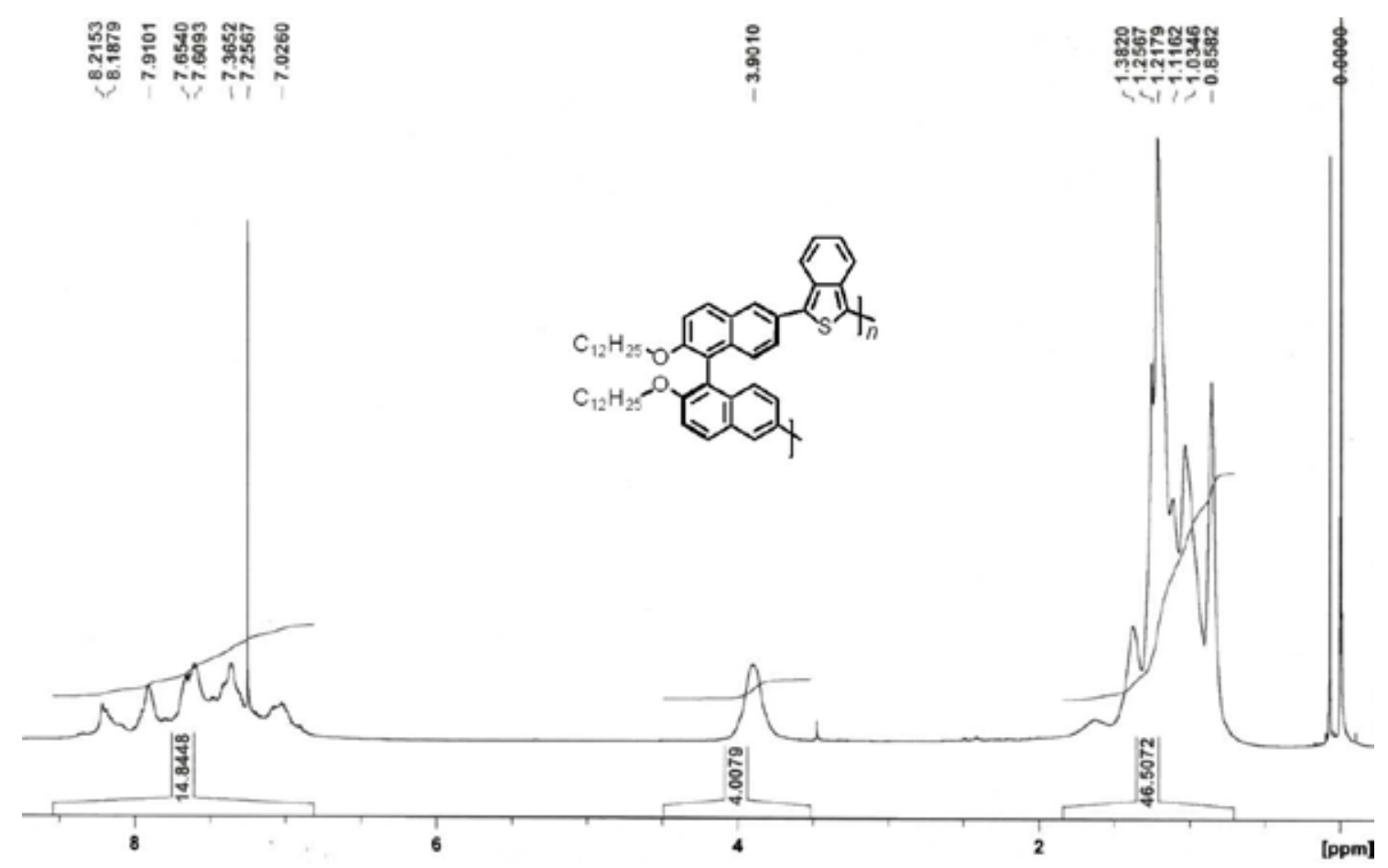

Figure S5. ${ }^{1} \mathrm{H}$ NMR spectrum (600 MHz) of P(Bn-ITN).

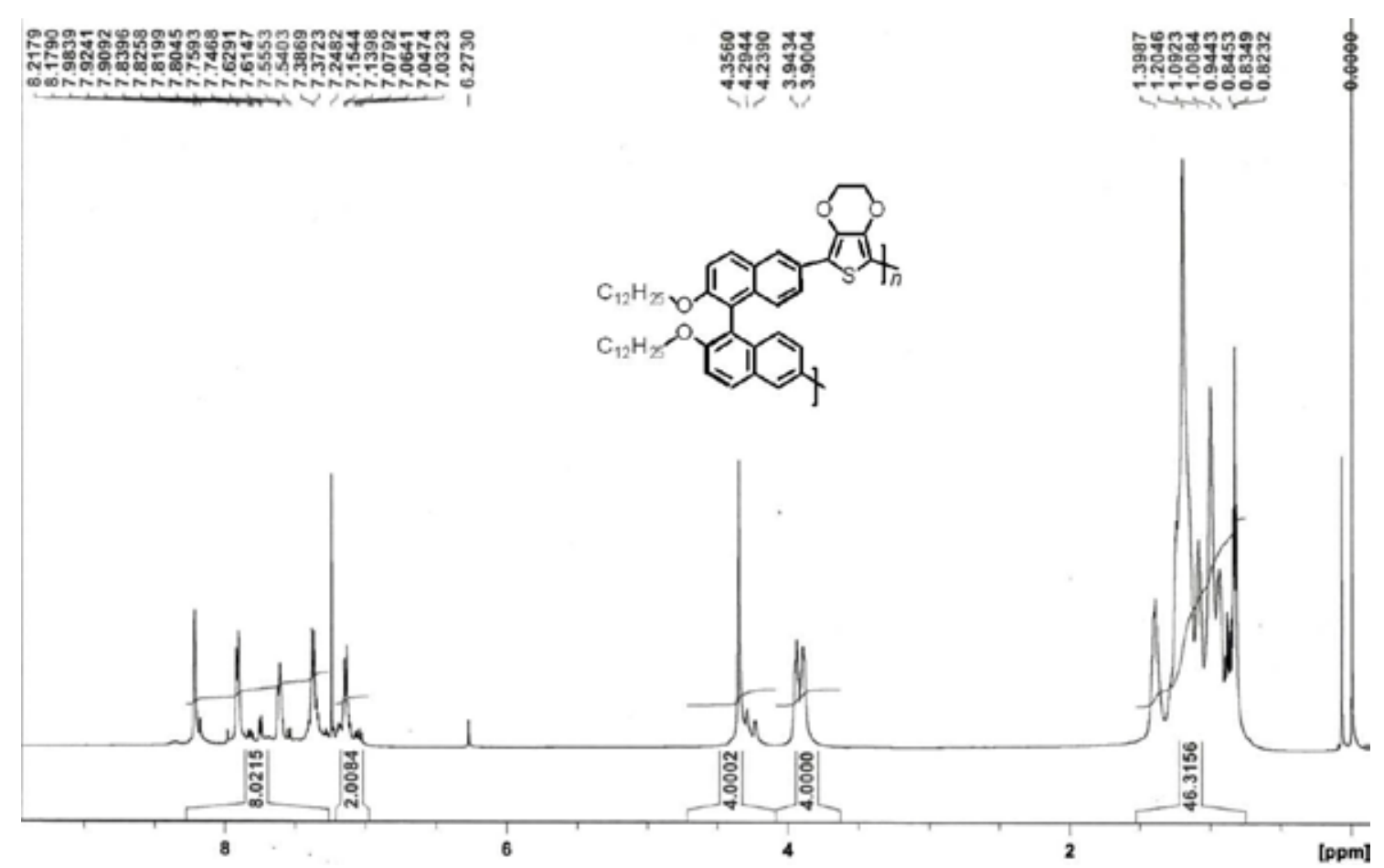

Figure S6. ${ }^{1} \mathrm{H}$ NMR spectrum (600 MHz) of P(Bn-EDOT). 


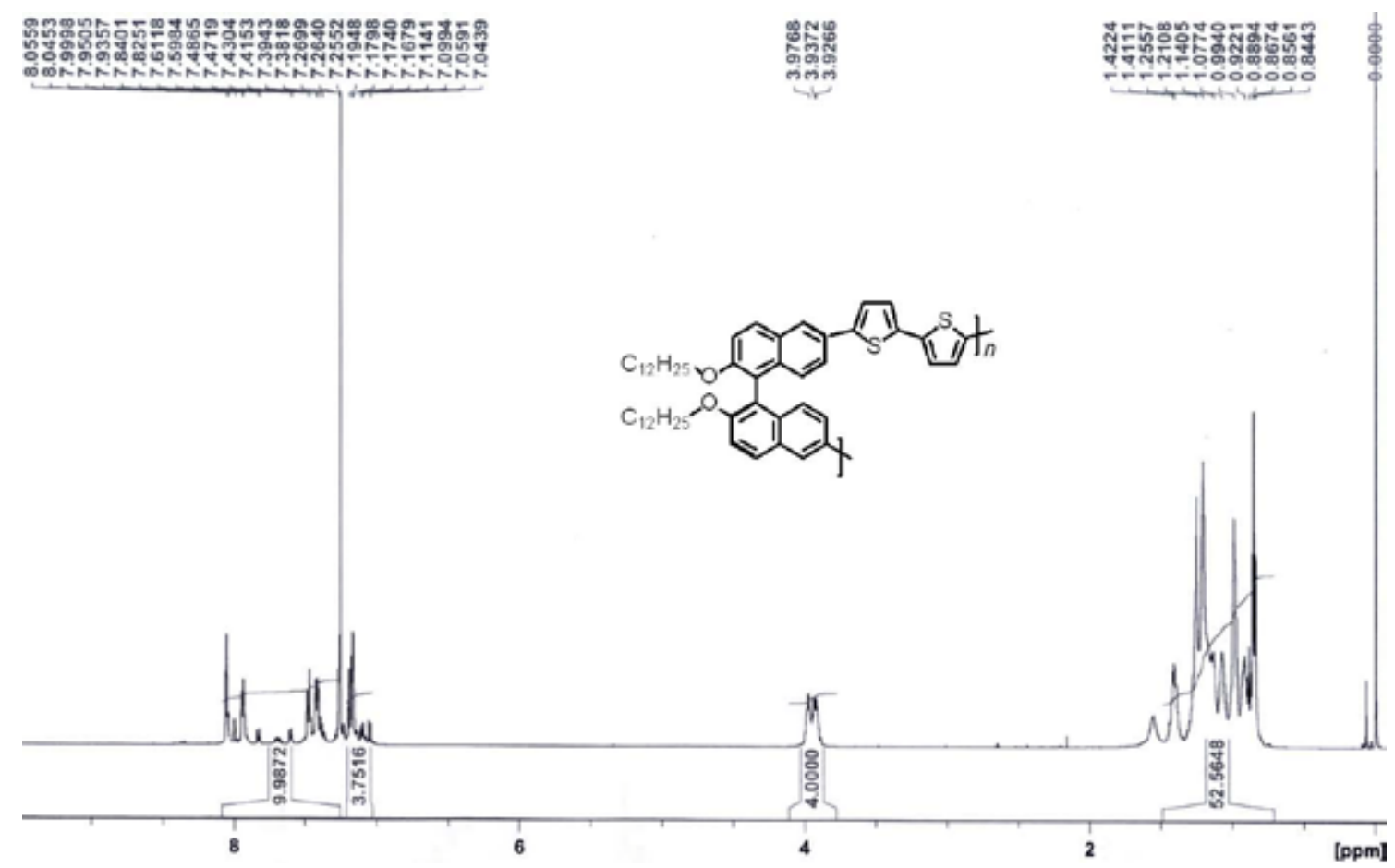

Figure S7. ${ }^{1} \mathrm{H}$ NMR spectrum (600 MHz) of P(Bn-BT).
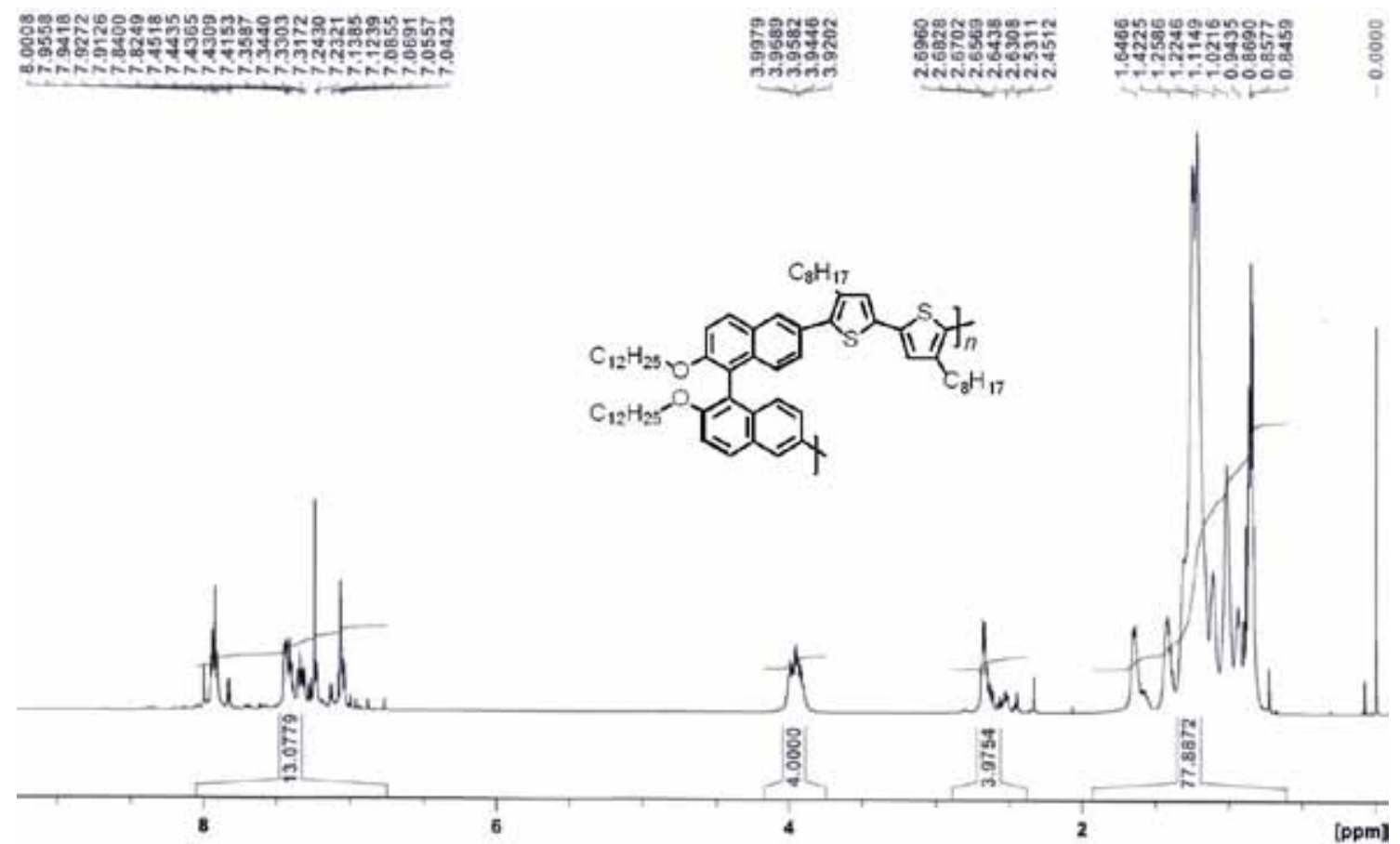

Figure S8. ${ }^{1} \mathrm{H}$ NMR spectrum (600 MHz) of P(Bn-B8T). 


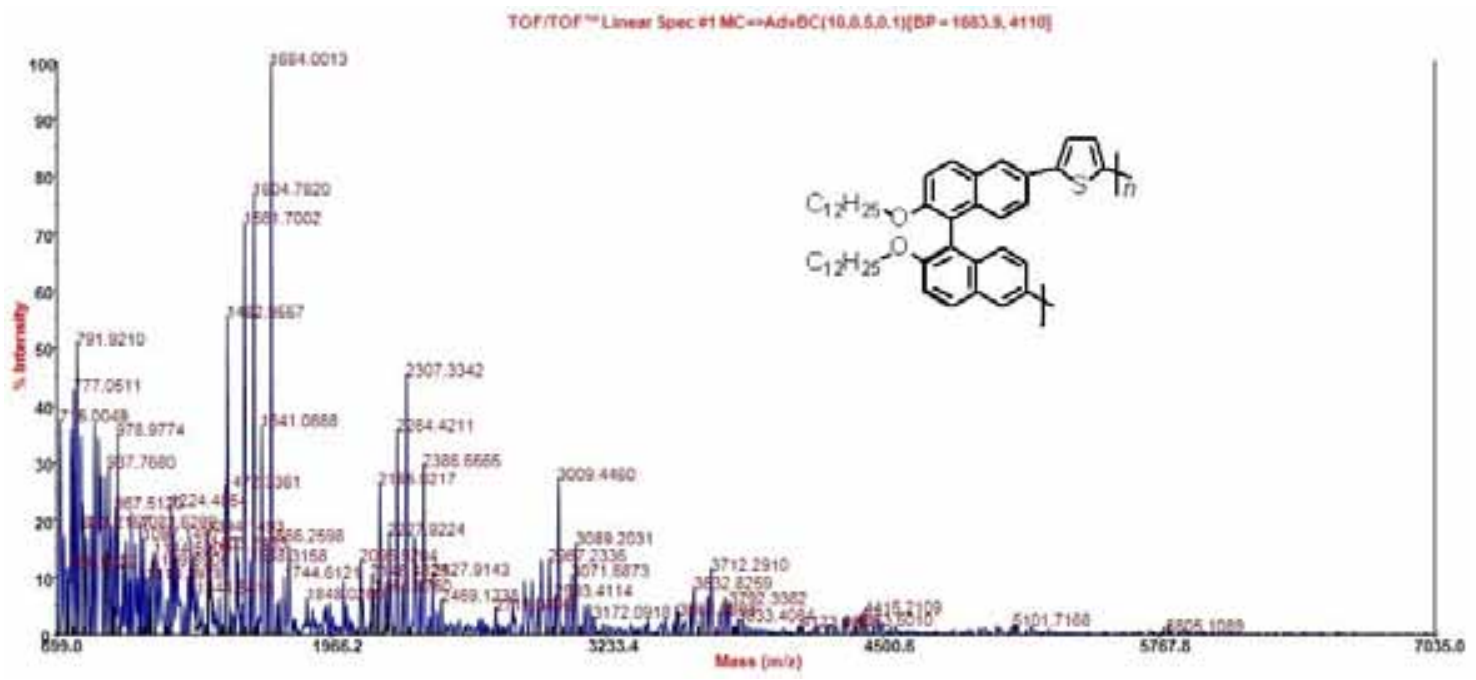

Figure S9. MALDI-TOF-MS spectrum of $\mathrm{P}(\mathrm{Bn}-\mathrm{T})$.

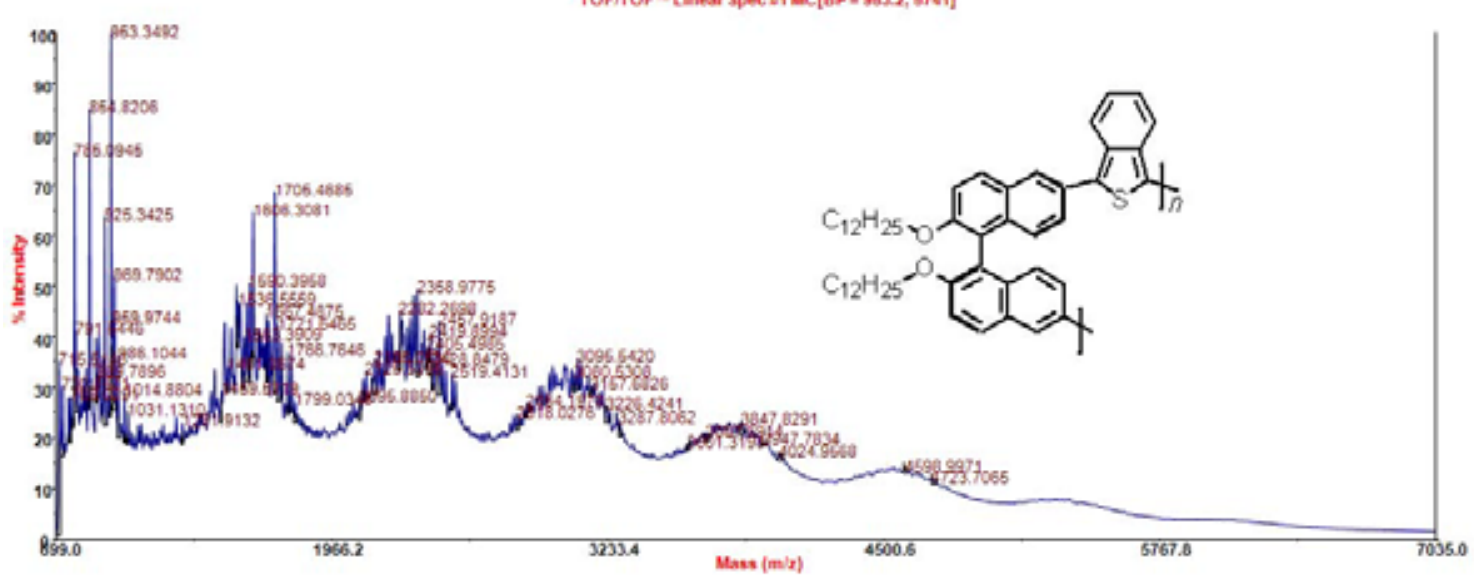

Figure S10. MALDI-TOF-MS spectrum of P(Bn-ITN).

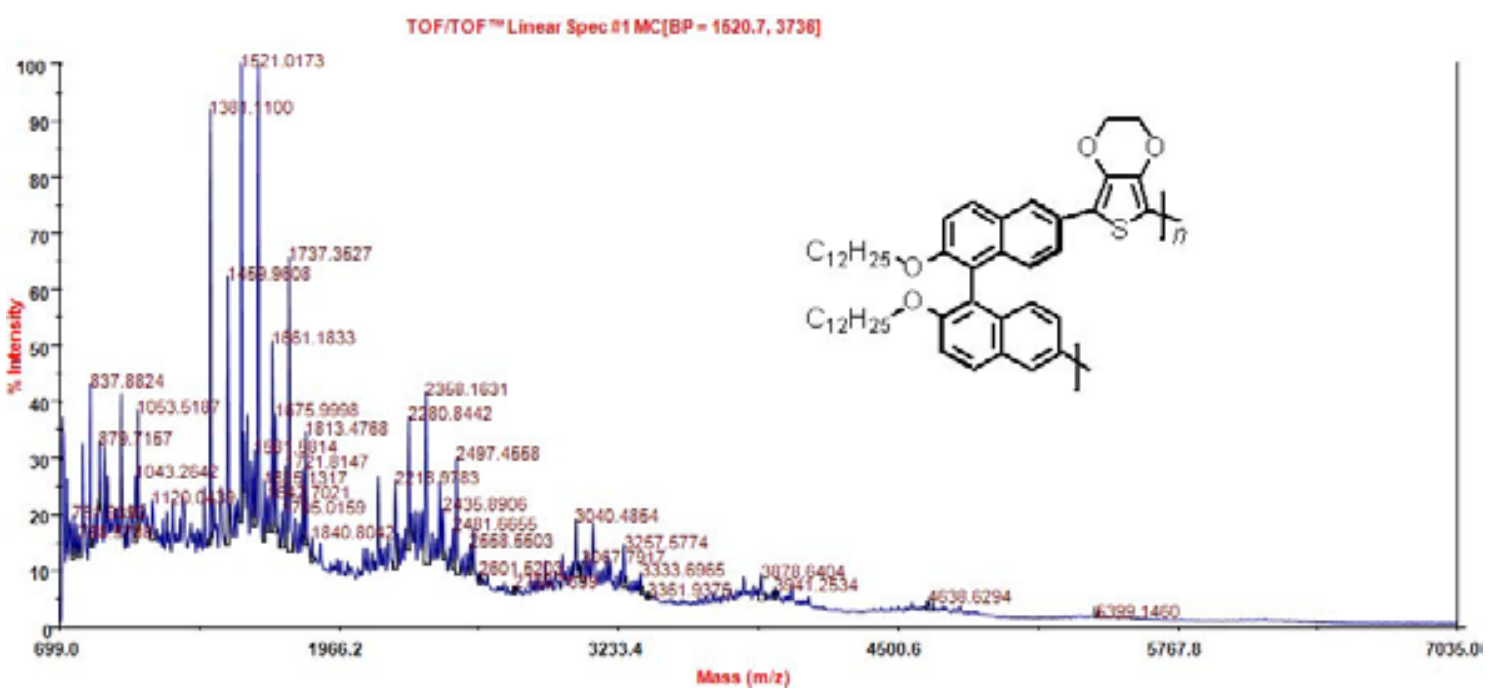

Figure S11. MALDI-TOF-MS spectrum of P(Bn-EDOT). 


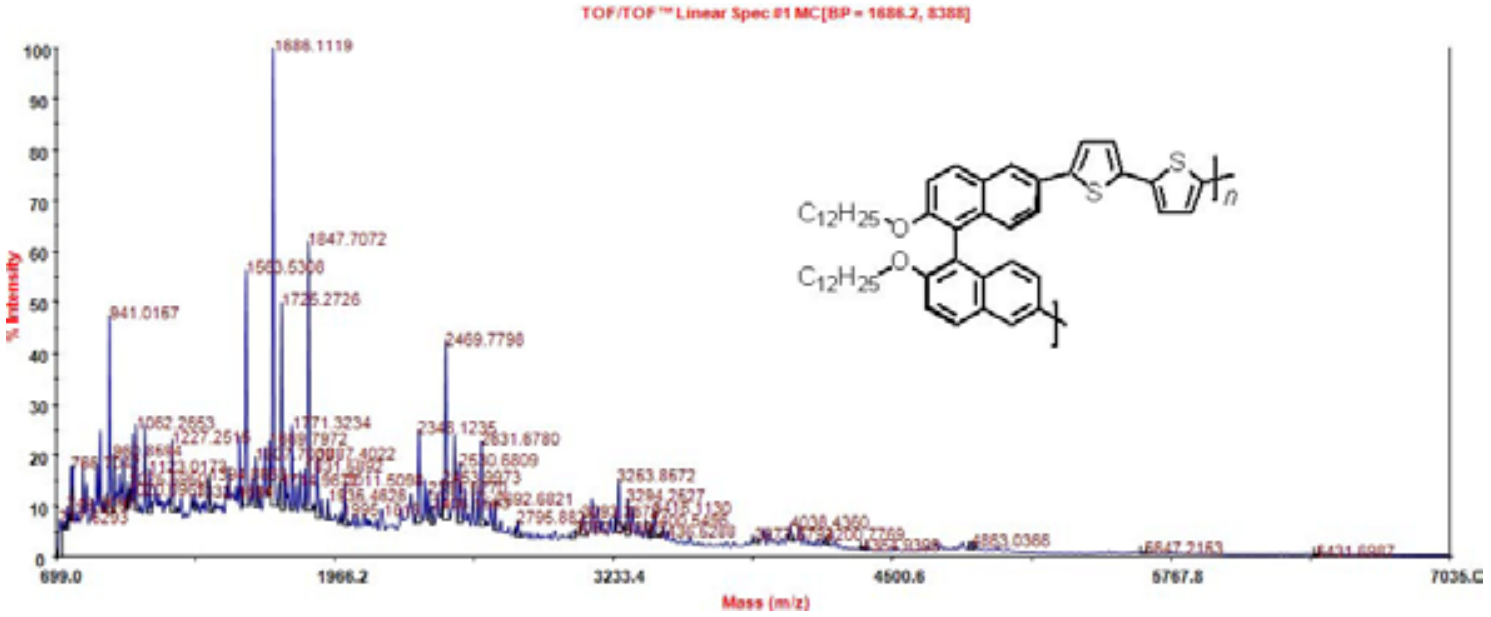

Figure S12. MALDI-TOF-MS spectrum of P(Bn-BT).

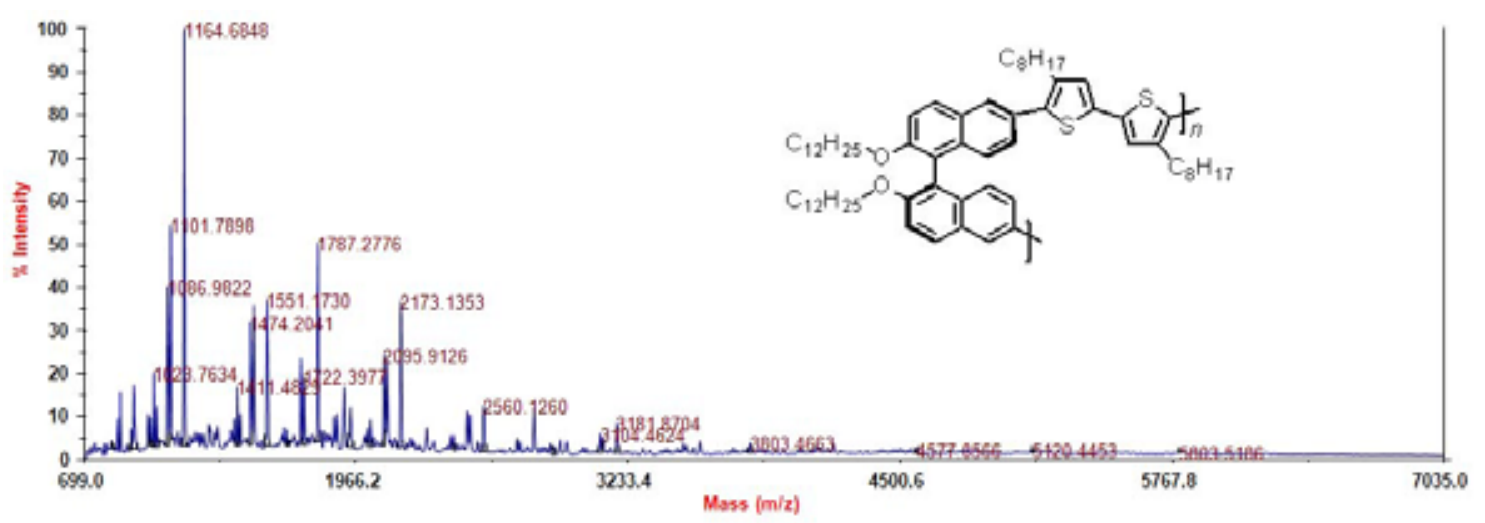

Figure S13 MALDI-TOF-MS spectrum of P(Bn-B8T). 